(C) 2022, The Authors. Published by Elsevier Inc. and Fass Inc. on behalf of the American Dairy Science Association ${ }^{\circledR}$. This is an open access article under the CC BY license (http://creativecommons.org/licenses/by/4.0/).

\title{
Effect of a milk byproduct-based calf starter feed on dairy calf nutrient consumption, rumen development, and performance when fed different milk levels
}

\author{
S. D. Parsons, ${ }^{1} \odot$ M. A. Steele, ${ }^{1} \odot$ K. E. Leslie, ${ }^{2} \odot$ D. L. Renaud, ${ }^{2} \odot$ C. N. Reedman, ${ }^{2} \odot$ C. B. Winder, ${ }^{2} \odot$ \\ and T. J. DeVries ${ }^{1 *}$ (1) \\ ${ }^{1}$ Department of Animal Biosciences, University of Guelph, Guelph, ON, N1G 2W1, Canada \\ ${ }^{2}$ Department of Population Medicine, Ontario Veterinary College, University of Guelph, Guelph, ON, N1G 2W1, Canada
}

\begin{abstract}
The objective of this study was to investigate the effects of a milk byproduct-based starter pellet, high in lactose, on feed intakes, growth, and rumen development when calves were fed either a high or low level of milk. This was done by using a $2 \times 2$ factorial design, with 120 Holstein heifer calves randomly assigned to 1 of 2 milk treatments and 1 of 2 feed treatments upon enrollment at birth. Calves were either assigned to a low (LM) or high (HM) level of milk replacer by an automated milk-feeding system for individuallyhoused calves. The LM treatment calves were offered $6 \mathrm{~L} / \mathrm{d}(150 \mathrm{~g} / \mathrm{L} ; 1.2 \mathrm{~L}, 5 \times / \mathrm{d})$, whereas HM treatment calves were offered $15 \mathrm{~L} / \mathrm{d}(150 \mathrm{~g} / \mathrm{L} ; 3 \mathrm{~L}, 5 \times / \mathrm{d})$ of milk replacer. Calves were also assigned to a milk byproduct- (whey) based starter feed treatment (WF), or a grain-based starter ration $(95 \%$ concentrate starter pellet, $5 \%$ chopped wheat straw) feed treatment (GF). All calves were offered their treatment feed starting on $\mathrm{d} 5$, with water offered ad libitum from d 0 . The WF treatment calves were offered $150 \mathrm{~g} / \mathrm{d}$ of the milk byproduct-based pellet until they consumed the entirety for 2 out of 3 consecutive days. At this point, WF treatment calves received $150 \mathrm{~g}$ of the milk byproduct-based pellet top dressed onto the grain-based ration to allow for ad libitum feed consumption until weaned, when they only received the grain-based ration postweaning (d 64-77). Calves on the GF feed treatment received only the grain-based ration. All calves were gradually weaned from d 43 to 63 . By design, calves on the HM treatment consumed greater levels of milk than LM treatment calves for the majority of the days in the preweaning phase $(8.9 \pm 0.11$ vs. $5.5 \pm 0.11 \mathrm{~L} / \mathrm{d} ; \mathrm{SE})$. Calves on the GF and WF treatments consumed similar amounts of milk in the preweaning phase $(7.2 \pm 0.11$
\end{abstract}

Received July 15, 2021.

Accepted September 3, 2021.

*Corresponding author: tdevries@uoguelph.ca vs. $7.2 \pm 0.11 \mathrm{~L} / \mathrm{d}$ ); however, there was a milk and feed treatment interaction detected for milk consumption in the weaning phase, with HM-GF calves drinking more milk than the other treatments and HM-WF calves drinking more milk than both LM-GF and LM-WF calves. The WF treatment calves had greater solid feed intake during the preweaning phase than GF treatment calves, with no feed intake differences in the weaning or postweaning phases. The WF calves drank more water in the preweaning phase than GF calves. Average daily gain was similar throughout the study between the GF and WF treatment calves. Rumen physiological measures were all similar by the end of the trial (d 77) regardless of feed or milk treatment, suggesting similar rumen development postweaning. Overall, regardless of the level of milk fed, offering the milk byproduct-based starter pellet may increase preweaning feed intake, along with water consumption. However, both feed and milk treatments had similar performance and rumen development measures by the end of the trial.

Key words: dairy calf, milk level, whey, growth, intake

\section{INTRODUCTION}

Improvements to performance and welfare can be achieved by offering calves higher levels of milk early in life ( $\geq 20 \%$ of BW by volume), compared with restrictive milk-feeding programs ( $\sim 10 \%$ of $\mathrm{BW}$ by volume) (Khan et al., 2011; Schäff et al., 2016; Rosenberger et al., 2017). As the benefits of higher milk-feeding programs have become more evident, producers have begun to increase their adoption of these programs (Medrano-Galarza et al., 2017; Winder et al., 2018). However, feeding higher levels of milk comes with the challenge of ensuring sufficient solid feed consumption before and during weaning (Jasper and Weary, 2002; Terré et al., 2007). Calves have a natural preference for milk (Jung and Lidfors, 2001; de Passillé and Rushen, 2006), and thus will consume less solid feed when offered higher milk-feeding programs (Terré et al., 2007; 
Raeth-Knight et al., 2009; Miller-Cushon et al., 2013). This reduction in solid feed intake can delay rumen development and increase challenges for the calf during and postweaning (Terré et al., 2007; Hill et al., 2010, 2016). Weaning is a stressful period in the life of a calf (Weary et al., 2008) and can have detrimental effects on behavior, physiology, and performance if not done properly, and results in a marked decrease in energy intake during this period (Budzynska and Weary, 2008; Sweeney et al., 2010; Steele et al., 2017). Thus, it is crucial that producers adopt proper management to optimize solid feed consumption before and during weaning to maintain growth and prevent loss of growth advantages during the weaning transition.

Commercial starter feeds are typically high in easily fermentable carbohydrates and may not be the most palatable and digestible feed for calves (Drackley, 2008; Khan et al., 2016). Preweaning calf digestive tracts are equipped for efficiently digesting milk as a primary source of energy (Meale et al., 2017). Therefore, it is predicted that feeding a milk byproduct (whey)-based calf starter, which is high in lactose (Terré et al., 2016), may increase calf acceptability and digestibility of solid feed, increasing feed consumption early in life. Novel starter feeds that are more palatable and accepted by calves, and potentially easier for them to digest while the rumen is still developing, need to be studied.

The idea of providing a milk byproduct-based starter to calves was investigated decades ago but has been scarcely investigated since. Past research suggests inconclusive results regarding the effect of these starter feeds when calves were restricted in their milk-feeding level ( $\leq 10 \%$ BW; Morrill and Dayton, 1974; Fisher and Buckley, 1985; DePeters et al., 1986). Terré et al. (2016) recently studied a pelleted feed based on whey concentrate and soybean meal compared with a conventional concentrate feed and concluded that when the wheybased starter was fed alone for the first $15 \mathrm{~d}$ of life (at $150 \mathrm{~g} / \mathrm{d}$ ), calves increased their solid feed consumption and gain-to-feed ratio during that time. The calves in that study were only offered $5 \mathrm{~L} / \mathrm{d}$ of milk (Terré et al., 2016); therefore, there is a need to investigate the effects of feeding a milk byproduct (whey)-based starter feed on calves fed a higher level of milk, and to determine how the response compares to those fed a lower level of milk.

The objective of this study was to determine the effect of feeding a milk byproduct (whey)-based calf starter during the milk-feeding and weaning period on the feed intake, growth, and digestion efficiency of dairy calves fed 2 different levels of milk. It was hypothesized that calves fed the milk byproduct-based calf starter would start to consume solid feed earlier in life, experience improved rumen development, and have greater performance during and postweaning than calves fed a traditional grain-based calf starter. Further, it was hypothesized that calves fed high levels of milk would benefit more than restricted fed calves when offered the milk byproduct-based starter, as these calves are more prone to reduced solid feed intake before weaning.

\section{MATERIALS AND METHODS}

\section{Study Design and Treatments}

A power analysis (Morris, 1999; Hintze, 2008) was performed before the study for the primary response variables, including feed intake and BW. Estimates of variation for these variables (mean $\mathrm{CV}=15 \%$ ) were based on previously reported values (Eckert et al., 2015; Overvest et al., 2016; Parsons et al., 2020). From the power analysis, it was determined that at $80 \%$ power, treatment differences of $\sim 8 \%$ could be detected at this sample size ( $\mathrm{n}=30$ calves per treatment combination). Using a $2 \times 2$ factorial design trial, calves were randomly assigned at birth to 1 of 2 milk-feeding treatments and 1 of 2 solid feed treatments. Random assignment to treatment was done by using a random number generator in Microsoft Excel (version 16.0; Microsoft Corp.) to generate a random order of the 4 treatments investigated in this trial, while also accounting for the 2 additional treatments (an additional dose of meloxicam on $\mathrm{d} 3$ postdisbudding versus no dose) in the collaborating disbudding trial. This random order of treatments was then repeated until all calves were assigned a milk level and solid feed treatment. The primary author of this paper oversaw enrollment of the calves based on the predetermined treatment assigned to the next calf born. The primary author was not blinded to treatments, as they were responsible for programming the automated milk-feeding system (AMF) that fed the calves, training calves to drink on the AMF, and solid feeding the calves daily.

Calves were assigned to either a high milk-feeding level (HM; $\mathrm{n}=60)$ or a restrictive milk-feeding level $(\mathbf{L M} ; \mathrm{n}=60)$, and to either a grain-based feed $(\mathbf{G F}$; $\mathrm{n}=60$ ) or milk byproduct (whey)-based feed (WF; $\mathrm{n}=60$ ) treatment. Calves on the HM milk-feeding treatment were offered a total of $15 \mathrm{~L} / \mathrm{d}$, compared with calves on the LM milk-feeding treatment who were offered a total of $6 \mathrm{~L} / \mathrm{d}$, once trained on the AMF at d 2. Total milk-feeding quantities and meal size varied depending on the treatment assigned. Calves assigned to the HM milk-feeding treatment were offered $3 \mathrm{~L}$ of milk at each of the 5 feedings, for a total of $15 \mathrm{~L} / \mathrm{d}$ from d 2 to 42. Calves on the LM milk-feeding treatment were offered $1.2 \mathrm{~L}$ of milk at each of the 5 feedings, for a total of $6 \mathrm{~L} / \mathrm{d}$ from $\mathrm{d} 2$ to 42 . Calves on the GF treat- 
ment were offered a ration made up of $95 \%$ calf pellet (20\% CP, Bionic Calf Grower Pellet, Grand Valley Fortifiers) and $5 \%$ chopped wheat straw $(2.5 \mathrm{~cm}$ in length) on an as-fed basis (Table 1 ). This ration was mixed in 200-kg batches by a calf feed mixer (Vertablend 4200 Self Propelled calf feed mixer; Vertablend MFG Inc.). Calves on the WF treatment were offered $150 \mathrm{~g} / \mathrm{d}$ of the milk byproduct-based starter feed (LifeLaunch 4C; Grand Valley Fortifiers) until they consumed the entire $150 \mathrm{~g} / \mathrm{d}$ (as fed) on 2 out of 3 consecutive days. Once that occurred, $150 \mathrm{~g} / \mathrm{d}$ of the milk byproduct-based starter feed was top dressed onto the grain-based starter feed and straw mixture to allow for ad libitum solid feed consumption until the end of weaning. Once the calves were weaned, all calves were offered the same grain-based ration (95\% of grain-based starter pellet, $5 \%$ chopped wheat straw) from d 64 to 77 .

\section{Animals, Housing, and Management}

This study took place at the University of Guelph, Elora Research Station-Ontario Dairy Research Cen- tre (Elora, Ontario, Canada). There were 120 female Holstein calves enrolled and managed under the guidelines of the Canadian Council of Animal Care (2009). All study techniques were reviewed and approved by the University of Guelph Animal Care Committee (AUP\#3722). The first calf was enrolled on October 7, 2019, and the last calf was enrolled September 14, 2020, with each enrolled calf subsequently followed for $77 \mathrm{~d}$. Calves were born in individual calving pens and were assessed at birth for health by assessing vigor and appetite during the first $2 \mathrm{~d}$; all heifer calves were deemed healthy and enrolled. Three calves were euthanized throughout the trial, as follows: 1 for severe respiratory distress due to pneumonia and 2 due to injuries; these calves were subsequently replaced with additional calves to achieve our target sample size. At birth (d 0), calves were tagged with a National Livestock Identification for Dairy tag (Allflex), their umbilici were dipped in $2.5 \%$ iodine solution to prevent infection, and they each received a subcutaneous injection of $1.5 \mathrm{~mL}$ of vitamin E-selenium (Dystosel, Zoetis Inc.). Within 2 $\mathrm{h}$ of birth (d 0), or first thing in the morning if calves

Table 1. Ingredient and chemical composition (\% of DM unless otherwise noted; mean \pm SD) of the components of calf starter feeds, grainbased ration, milk byproduct-based feed, and milk replacer fed to calves

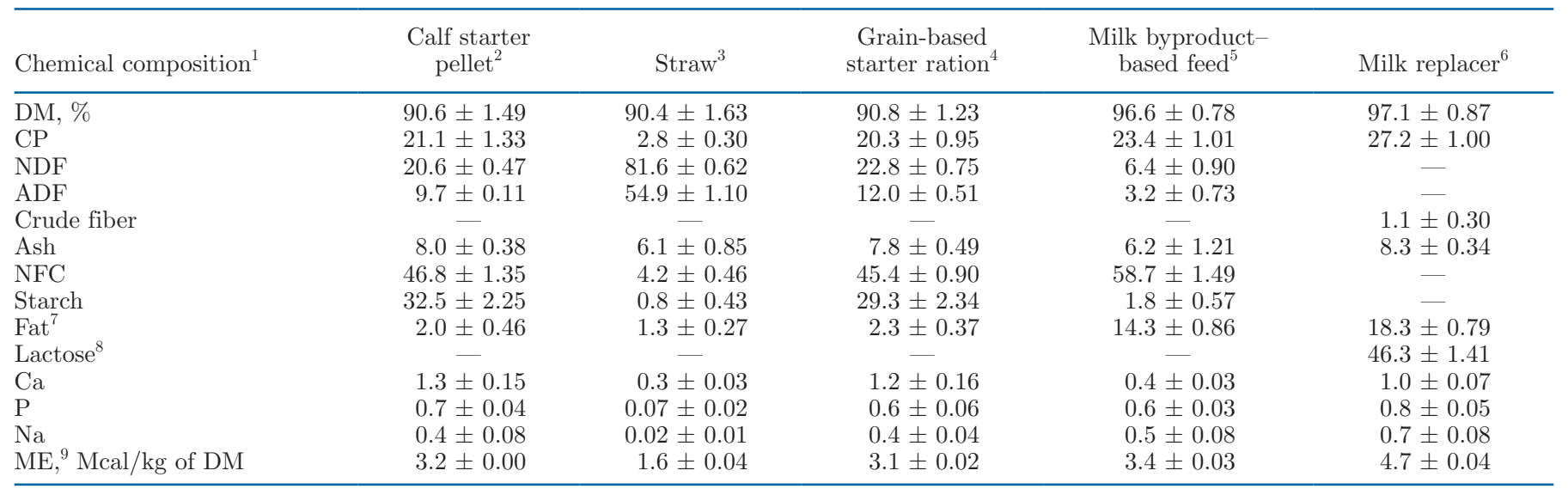

${ }^{1}$ Chemical analysis was performed by A\&L Laboratory Services Inc. (London, ON, Canada).

${ }^{2}$ Calf starter pellet was supplied by Grand Valley Fortifiers Ltd. (Bionic Calf Grower Pellet, Grand Valley Fortifiers). Included ingredients were as follows: corn chop, soybean meal $48 \%$, wheat shorts, ground barley, hard west wheat, high-bypass soybean meal, soya hulls, beat pulp ground (Floradale Feed Mill), molasses, calcium carbonate 39\%, Pelltech (Borregaard LignoTech), salt, kelp meal (Tasco; Acadian Seaplants), dicalcium phosphate 21\%, magnesium potassium sulfate (Dynamate; Mosaic), magnesium oxide 56\%, dairy micro (Grand Valley Fortifiers), vitamin E, Cel-Max soluble concentrate powder (Pestell Nutrition), vitamin A/D/E 10/10/10, vitamin B complex calf micro (Grand Valley Fortifiers), Availa 4 (Zinpro), choline-70\% liquid, Bovatec 20\% (Zoetis Inc.), covotek 575 vanilla (Pancosma), selenium yeast 2000 (Angel Yeast Co., Ltd.), Xtract instant (Pancosma), Sucram 3D (Pancosma).

${ }^{3}$ Straw was chopped wheat straw cut to measure approximately $2.5 \mathrm{~cm}$.

${ }^{4}$ Grain-based starter ration was $95 \%$ calf starter pellet and $5 \%$ chopped wheat straw, mixed on an as-fed basis.

${ }^{5}$ Milk byproduct-based feed was supplied by Grand Valley Fortifiers (Life Launch 4C). Included ingredients were as follows: roasted soybeans 38\%, whey powder (Grober Nutrition), whey permeate (Grober Nutrition), 7/60 coconut fat 1022 (Grober Nutrition), Life Launch calf micro (Grand Valley Fortifiers), citric acid, covotek 575 vanilla (Pancosma).

${ }^{6}$ Milk replacer was supplied by Grand Valley Fortifiers.

${ }^{7}$ Fat for the milk replacer was done by an acid hydrolysis test (AOAC International, 1995; method 954.02).

${ }^{8}$ Lactose is assumed to be $100-\mathrm{CP}-$ fat - ash.

${ }^{9}$ Metabolizable energy was calculated using NRC (2001) equations. 
were born between 1900 and $0430 \mathrm{~h}$, calves received $3 \mathrm{~L}$ of colostrum. Thirty minutes before the first colostrum feeding, calves received a $3-\mathrm{mL}$, orally administered, vaccination to prevent diarrhea caused by bovine rotavirus and bovine coronavirus (Calf-Guard; Zoetis Inc.). Colostrum $\geq 22 \%$ brix according to the Calf Lab refractometer (Golden Calf Company LLC) was fed according to Buczinski and Vandeweerd (2016). Each calf received their dam's colostrum, unless the quality was too low, in which case frozen colostrum $(\geq 22 \%$ Brix) was fed. The colostrum was offered by bottle, but fed via an esophageal tube feeder if the calf did not voluntarily suckle the entire $3 \mathrm{~L}$ from the bottle. Within 6 to $12 \mathrm{~h}$ after the first feeding, another $3 \mathrm{~L}$ of colostrum was fed. On d 1, calves were offered 3 feedings of transition milk in 2-L quantities by bottle. Beginning on d 2 until d 63, calves were fed an acidified milk replacer at a concentration of $150 \mathrm{~g} / \mathrm{L}(5.4 \mathrm{pH}, 26 \% \mathrm{CP}, 18 \%$ crude fat; BioForce Acidified Milk Replacer, Grand Valley Fortifiers) by an AMF.

Within $2 \mathrm{~h}$ of birth, or first thing in the morning if calves were born between 1900 and $0430 \mathrm{~h}$ (when no staff were present), calves were moved into 1 of 4 calf nursery rooms, each with a total of 11 individual pens $(152 \times 167 \mathrm{~cm}$, width $\times$ length $)$. Calves were housed in individual pens from birth until d 78 (at which point study observations were complete), when they were then moved into a group-housing system. All calves had visual, auditory, and limited physical contact with neighboring calves, as all 4 sides of the individual pens were vertical steel bars. On the front end of the pen, where the AMF would stop, one hole was in the gate to allow the calf to reach their head through and consume milk from the AMF. On the back end of the pen, opposite where the AMF stopped and offered milk, there were 2 openings in the gate, with 2 8-L buckets attached to provide access to both water and solid feed. Each calf nursery had an AMF (Calf Rail; Forster Technik) placed in the center aisle of the nursery room, feeding milk to the calves in the individual pens on the right side and left side of the nursery room. There was 1 calf feeder (DeLaval calf feeder CF $1000+$, DeLaval Canada) in every other room to mix milk replacer for 2 AMF in 2 separate nursery rooms. The AMF system ran 5 times per day, at 0500, 0900, 1300, 1700, and $2100 \mathrm{~h}$ and performed an automatic circuit cleaning after each feeding, with a manual cleaning of the teat and arm of the AMF performed by barn staff once per day. All calves had ad libitum access to water from birth, provided in one 8-L bucket attached to the pen, which was topped up as needed throughout the day. Calves received access to fresh solid feed daily, according to their assigned solid feed treatment start- ing at $\mathrm{d} 5$. All calves were gradually weaned off their milk level treatment by a continuous gradual program, where the AMF automatically decreased the total daily milk allowance in small, equal increments from d 43 to 63. All calves received no milk starting d 64 , but remained in their individual pen until the end of $\mathrm{d} 77$ for their postweaning phase. Staff checked the AMF daily at $1730 \mathrm{~h}$ to identify calves that did not yet consume a minimum of $4 \mathrm{~L}$ for that day from the AMF. In that case, calves were then offered a bottle of milk to add up to the 4-L minimum consumption to ensure calves were offered at least $4 \mathrm{~L}$ of milk replacer per day, with the option to still consume their last feeding from the AMF (2100 h), after staff had left for the day. This also ensured calves assigned to the low level of milk were not consuming more total milk from the bottle and AMF than their entitled $6 \mathrm{~L} / \mathrm{d}$. As farm staff were responsible for checking the feeder and bottle feeding calves when needed, they were not blinded to treatments. All additional bottle feedings were recorded by staff, and later added to the quantity of milk consumed off the AMF each day, to determine total daily milk consumption for each calf.

Calf nursery rooms were artificially ventilated with an automatic positive-pressure forced-air system to maintain a constant temperature set at a minimum of $10^{\circ} \mathrm{C}$ by drawing air from the above attic or outside. Calf pens were scraped clean and rebedded with fresh wood shavings twice per week, and a fresh layer of bedding was provided daily. Lighting in each nursery was on from 0430 to $2300 \mathrm{~h}$ to ensure lights were on while the AMF was feeding the calves. From d 0 to 6 , all calves were given a daily oral dose $(2 \mathrm{~mL}$ per $10 \mathrm{~kg}$ of BW) of an antiprotozoal solution to reduce the clinical signs of cryptosporidiosis (Halocur, Merck Animal Health). All calves were vaccinated at d 42 and 63 with $1 \mathrm{~mL}$ of a respiratory vaccine (Inforce-3 intranasal spray; Zoetis Inc.) in each nostril for the prevention of bovine respiratory disease. Calves were disbudded as part of a collaborating research trial (Reedman, 2021), which used 80 of the same calves as the present trial. Disbudding occurred for all study calves between d 18 and 30 using a cautery iron (Express Pistol-Grip Dehorner, The Coburn Company, Inc.). Every calf received a lidocaine cornual nerve block 15 min before disbudding $(6 \mathrm{~mL}$ per side, lidocaine hydrochloride injection, $20 \mathrm{mg} / \mathrm{mL}$, Bimeda-MTC Animal Health Inc.), as described by Winder et al. (2017). At this time, each calf also received a subcutaneous injection in the neck of $0.5 \mathrm{mg} / \mathrm{kg}$ meloxicam (Metacam $20 \mathrm{mg} /$ $\mathrm{mL}$ Solution for Injection, Boehringer Ingelheim), a nonsteroidal anti-inflammatory drug. As part of the collaborating research trial, 45 of the calves received 
an additional $0.5 \mathrm{mg} / \mathrm{kg}$ subcutaneous injection of the nonsteroidal anti-inflammatory drug meloxicam on $\mathrm{d} 3$ after disbudding occurred. Calves that were not part of the collaborating trial were also disbudded in a similar fashion as previously described without the additional meloxicam dose on d 3 .

\section{Feed Consumption Measurements}

The AMF system software automatically measured calf milk replacer daily intakes. A backup of these data were downloaded weekly and later compiled for each calf. Fresh water and solid feed were provided each day in separate buckets, and the amount of each consumed were recorded manually at $0900 \mathrm{~h}$ each day. Solid feed was weighed daily, and feed intakes were calculated based on the weight of the offered and weight of the refused feed at the start of each day. The volume of water remaining daily was measured, and the quantity of water consumed daily was calculated using the amount that was offered and refused each day. Refusal feed samples were taken twice a week on Mondays and Thursdays to determine a weekly average DM for refused feed for each calf. Fresh feed samples of the grain-based ration, milk byproduct-based feed, and milk replacer were taken once per week, whereas feed samples of components of the grain-based ration (calf pellet and straw) were taken once per month. All feed samples were immediately frozen at $-20^{\circ} \mathrm{C}$ for later analysis. All feed samples were later thawed and subsequently dried in an oven at $60^{\circ} \mathrm{C}$ for $48 \mathrm{~h}$ to determine the DM content of the sample. After drying occurred, ration components (calf grain pellet and straw), grain-based ration (95\% pellet, $5 \%$ chopped straw), and milk byproduct-based feed samples were ground through a 1-mm sieve (model 4 Wiley Laboratory Mill, Thomas Scientific). Feed samples and milk replacer samples were then pooled by month and sent to A\&L Canada Laboratories Inc. (London, Ontario, Canada) for chemical composition analyses. Straw, pellet, grain-based ration, and milk byproduct feed samples were analyzed for ash $\left(550^{\circ} \mathrm{C}\right.$; AOAC International, 2000; method 942.05), CP ( $\times$ 6.25; AOAC International, 2000; method 990.03; Leco FP-628 Nitrogen Analyzer, Leco), ADF (AOAC International, 2000; method 973.18), NDF with heat-stable $\alpha$-amylase and sodium sulfite (AOAC International, 2000; method 2002.04), starch (heat-stable amylase and amyloglucosidase; AOAC International, 2000; method 996.11), and crude fat (AOAC International, 2000; method 920.39; Ankom XT15). Milk replacer samples were analyzed for $\mathrm{CP}(\mathrm{N} \times 6.25$; AOAC International, 2000; method 990.03; Leco FP-628 Nitrogen Analyzer, Leco), crude fiber (AOAC International, 2000; method
Ba 6a-05; Ankom Bag Technology), and fat (total fat by acid hydrolysis using Ankom $\mathrm{HCl}$ Hydrolysis System; AOAC International, 1995; method 954.02, section 4.5.02). Metabolizable energy was calculated using NRC (2001) equations for the milk replacer and the GF ration and milk byproduct-based feed samples. An average ME was calculated for the milk replacer and both types of feed provided and used to calculate ME intake. When calves on the milk byproduct-based feed treatment had $150 \mathrm{~g} / \mathrm{d}$ of the milk byproduct-based feed top dressed onto the GF ration, it was assumed the entire $150 \mathrm{~g} / \mathrm{d}$ was consumed, with the refused feed assumed to be only the grain-based starter feed ration, when calculating ME intake for these calves. The DMI was calculated by correcting the kilograms of solid feed consumed by the average DM of the corresponding refusal samples for that week of data for each calf.

\section{Growth and Health Measurements}

All calves were weighed on $\mathrm{d} 0$, when they were moved into their individual pens, using an individual calf BW scale (1-2-3 animal scale, Bosche GmbH \& Co. KG). Calves were measured for BW and body size (hip height, heart girth, middle girth) on 2 consecutive days (every Tuesday and Wednesday at $0700 \mathrm{~h}$ ) to calculate an average for that week. These measurements were used to calculate ADG per week for each calf, as well as body size changes per week.

Serum total protein (STP) values were measured for each calf between d 2 and 8 (Wilm et al., 2018). Blood was collected from the jugular vein into a $10-\mathrm{mL}$ sterile blood collection tube without anticoagulant (BD Vacutainer; Becton, Dickinson and Co.). The blood was allowed to clot and then centrifuged at $1,500 \times g$ for $15 \mathrm{~min}$. Sixty microliters of serum were pipetted from the tube to a digital refractometer (Kernco KS-0050 digital refractometer, Kernco Instruments Co. Inc.) to determine STP. Calves were categorized as having failed transfer of passive immunity (FTPI) when STP was $<5.5 \mathrm{~g} / \mathrm{dL}$ (Buczinski et al., 2018). Calf health was checked daily by farm staff based on their standard operating procedures to identify and treat disease. According to these, a veterinarian came to diagnose suspected cases of bovine respiratory disease (BRD) before treatment with antibiotics. Neonatal calf diarrhea (NCD) was diagnosed by farm staff based on fecal consistency score, with any fecal score of $\geq 2$ considered NCD (McGuirk, 2008), which was then treated with electrolytes twice per day until fecal score improved. If calves had NCD and also experienced a high temperature, calves received a subcutaneous injection of 0.5 $\mathrm{mg} / \mathrm{kg}$ meloxicam. 


\section{Rumen Physiological Measurements}

Blood Measurements. Calf blood was sampled to determine blood BHB concentration as a proxy for rumen physiological development (Deelen et al., 2016) on d $36,57,70$, and 77 . Tests were performed calf-side by drawing a small amount of blood $(<1 \mathrm{~mL})$ from the coccygeal vein using a 22 -gauge, $2.54-\mathrm{cm}$ needle and a 1 -mL syringe at approximately $1200 \mathrm{~h}$. Using a handheld meter (FreeStyle Precision Neo; Abbott Diabetes Care) with blood ketone test strips (FreeStyle Precision $\beta$-Ketone; Abbott Diabetes Care), a droplet of blood was placed on the strip and the reader indicated the blood $\mathrm{BHB}$ concentration $(\mathrm{mmol} / \mathrm{L}$; validated by Deelen et al., 2016).

Rumen Fluid VFA and pH Measurements. Rumen fluid samples were collected on d $36,57,70$, and 77, 3 to $4 \mathrm{~h}$ after the $0900 \mathrm{~h}$ AMF feeding (1200-1300 h), as described by Benschop and Cant (2009). Fluid was collected by passing a modified esophageal tube, with a metal strainer attached to a pliable plastic hose (with a $0.953 \mathrm{~cm}$ inside diameter), down the esophagus and into the rumen. Rumen fluid samples were drawn into the tube using a $60-\mathrm{mL}$ catheter tip syringe and then filtered through 4 layers of cheese cloth to remove any solid particles. The rumen fluid samples were tested for the $\mathrm{pH}$ level immediately with a $\mathrm{pH}$ meter that was calibrated before each sample (accumet AB150pH Benchtop Meter, Fisher Scientific). An 8-mL sample of rumen fluid was added into a $15-\mathrm{mL}$ conical tube that contained $2 \mathrm{~mL}$ of $25 \%$ meta-phosphoric acid for sample preservation, and subsequently frozen at $-20^{\circ} \mathrm{C}$ for later analysis of VFA. The collection apparatus was cleaned and disinfected with ethanol between calves to prevent contamination of samples.

Samples were thawed on ice, vortexed, and $2 \mathrm{~mL}$ of the sample was transferred into 2-mL Eppendorf tubes. These were immediately refrozen for transportation on dry ice to the University of Alberta (Edmonton, Ontario, Canada) for analysis of VFA. Volatile fatty acid analysis was determined by GC, as described by Schlau et al. (2012). In brief, once thawed, samples were centrifuged and $1 \mathrm{~mL}$ of sample was combined with $0.2 \mathrm{~mL}$ of isocaporic acid as an internal standard and assayed on a Varian gas chromatograph (model 3400; Varian Inc.). The total VFA concentrations in each sample were calculated by adding individual amounts of VFA together. The proportion (\%) of an individual VFA in each sample was calculated by dividing the amount of individual VFA by the total VFA and multiplying it by 100 .

Fecal Starch Measurements. Fecal samples were collected from each calf on d $36,57,70$, and 77 , at the same time as rumen fluid and blood samples for BHB were collected, as calves were already restrained. Calves were rectally stimulated using a sterile gloved finger, placing the fresh fecal sample in a sterile sample cup. Fecal samples were then immediately frozen at $-20^{\circ} \mathrm{C}$ before analysis at A\&L Canada Laboratories Inc. (London, ON, Canada) for fecal starch (heat-stable amylase and amyloglucosidase; AOAC International, 2000; method 996.11).

\section{Statistical Analyses}

All statistical analyses were conducted using SAS 9.4 software (SAS Institute Inc.). Significance was declared at $P \leq 0.05$, and tendencies were reported if $0.05<$ $P \leq 0.10$. Before analyses, all data were screened for normality using the UNIVARIATE procedure of SAS. All variables met assumptions of normality. All calves enrolled on the trial were included in analyses. Outliers ( $\geq 3 \mathrm{SD}$ from the mean) in data for individual calves (for individual days or weeks) were explored to ensure data were not erroneous; if correct but still an outlier, they were removed before analyses. For each model tested, interactions were further investigated when an interaction $P$-value was $\leq 0.05$.

To investigate the effect of treatments (milk and feed treatments) on measures of intakes and growth, data collected were summarized and analyzed within the following phases: preweaning (d 1-42), weaning (d 43-63), and postweaning (d 64-77). Data were analyzed using the MIXED procedure of SAS, with day as a repeated measure for measurements of intakes, and week as a repeated measure for measurements of growth. Calf within assigned nursery room was the subject of the repeated statement, and room was the random effect. The model included the fixed effects of milk treatment, feed treatment, day or week depending on the frequency of measurements taken, and the interaction terms for milk treatment $\times$ feed treatment, milk treatment $\times$ day or week, feed treatment $\times$ day or week, and milk treatment $\times$ feed treatment $\times$ day or week. To analyze VFA, fecal starch, and blood BHB outcomes, similar PROC MIXED models were developed without summarizing or analyzing by phase. To analyze rumen fluid $\mathrm{pH}$, recorded $\mathrm{pH}$ data values were transformed back to $\mathrm{H}^{+}$ion concentrations and multiplied by 1,000 for analysis using PROC MIXED models similar to those used for VFA, fecal starch, and blood BHB. Following analysis, these values were then back-transformed to $\mathrm{pH}$ along with respective $95 \%$ confidence intervals. Birth BW, birth season, if calves were given an extra dose of meloxicam as part of the collaboration disbudding trial, and whether calves were diagnosed with NCD or 
BRD versus not were tested as covariates, along with their interaction terms with the milk treatments and feed treatments. The birth season of each calf was classified as fall (September-November), winter (December-February), spring (March-May), and summer (June-August). If the tested covariates were $>0.05$, then they were removed. Birth season was retained in models for measurements of VFA, BW, height gain, and intakes. Birth $\mathrm{BW}$ and birth $\mathrm{BW} \times$ milk treatment were retained in the model for measurements of milk, total DMI, DMI, ratio of gain to ME intake, and ADG. Birth BW was also retained as a covariate for BW, heart girth gain, height gain, and water intake. The treatment based on the collaborating disbudding trial (an extra dose of meloxicam versus none) was retained as a covariate for BW, milk intake, DMI, total DMI, solid feed DMI as \% BW, and ME intake outcomes. Whether calves were diagnosed with NCD or not was retained as a covariate for measurements of DMI, total DMI, and ME intake outcomes.

Covariance structure was selected based on the best fit according to Schwarz's Bayesian information criterion. The covariance structures that were used included compound symmetry (DMI as \% BW), heterogeneous compound symmetry (ADG, middle girth gain, butyric, isobutyric, isovaleric, valeric acid, and fecal starch), first-order autoregressive (heart girth gain, rumen fluid $\mathrm{pH}$ ), and first-order heterogeneous autoregressive (feed, water, and milk intakes, ME intake, gain to ME intake, BW, height gain, caporic, acetic, and propionic acid, total VFA, and BHB).

To determine differences in birth BW and STP concentrations, PROC MIXED was used with milk treatment, feed treatment, milk treatment $\times$ feed treatment, and calf within milk treatment $\times$ feed treatment as the random effect. To determine differences in cases of NCD, BRD, or FTPI, a multivariable logistic regression analysis with a binary distribution and logit link using the GLIMMIX procedure of SAS was used, where the variables were treated as categorical. The model included the fixed effects of both treatments (milk and weaning treatments), milk treatment $\times$ feed treatment, and calf within treatment interaction as the random effect. When differences for milk, feed treatments, or interactions were detected, the PDIFF statement was added to the LSMEANS statement to compare means. Means for individual treatment combinations are presented in tables. Data for main treatment effects (HM vs. LM, and GF vs. WF) are presented in figures when interactions of those main effects were not present. All other main treatment means, along with all those data that are not shown in figures, can be found in the supplemental materials (https://doi.org/10.5683/SP3/ RWCQXV).

\section{RESULTS}

No treatment differences were detected in birth BW $(\mathrm{HM}-\mathrm{GF}=41.1 \mathrm{~kg} ; \mathrm{HM}-\mathrm{WF}=41.0 \mathrm{~kg} ; \mathrm{LM}-\mathrm{GF}=$ 40.8; LM-WF $=39.8 \mathrm{~kg} ; \mathrm{SE}=0.87 ; P \geq 0.39)$. No treatment differences $(P \geq 0.87)$ were detected for STP concentration, with the average STP concentration for all treatments being $5.8 \pm 0.14 \mathrm{~g} / \mathrm{dL}( \pm \mathrm{SE})$. No differences between treatments were detected for the number of calves classified as FTPI (HM-GF $=7$; HM-WF $=9$; $\mathrm{LM}-\mathrm{GF}=11 ; \mathrm{LM}-\mathrm{WF}=9 ; P \geq 0.40)$. A high incidence of NCD was diagnosed by farm staff during the study, with 88 calves having a case of NCD ( $73.3 \%$ of calves), and no treatment differences were detected for number of calves being diagnosed with NCD (HM-GF $=23$; $\mathrm{HM}-\mathrm{WF}=24 ; \mathrm{LM}-\mathrm{GF}=18 ; \mathrm{LM}-\mathrm{WF}=23 ; P \geq 0.26)$. Only 4 calves in the study were diagnosed with BRD (3.3\%), and no treatment differences were detected for calves diagnosed with $\mathrm{BRD}$ (HM-GF $=2$; HM-WF; $=$ $0 ; \mathrm{LM}-\mathrm{GF}=1 ; \mathrm{LM}-\mathrm{WF}=1 ; P \geq 0.34)$.

\section{Nutrient Consumption}

Milk consumption was similar for GF and WF treatment calves across milk treatments during the preweaning phase (Table 2). Preweaning, a milk treatment $\times$ day interaction was detected for milk intake, as expected due to treatment design (Table 2). Calves on the HM treatment consumed greater amounts of fluid milk (L/d; $P \leq 0.03$; Figure 1a and b; Supplemental File S1, https://doi.org/10.5683/SP3/RWCQXV) and unconstituted milk replacer $(\mathrm{kg} / \mathrm{d} ; P \leq 0.05$; data not shown) than LM treatment calves across d 4 to 5 and d 7 to 42 . During the weaning phase, there was a milk treatment $\times$ feed treatment interaction for fluid milk intake $(P=0.05$; Figure $1 \mathrm{a}$ and $\mathrm{b})$ and, consequently, unconstituted milk replacer $(P=0.05$; Table 2$)$. Across the weaning phase, calves consumed greater amounts of milk when on the HM-GF treatment $(6.5 \mathrm{~L} / \mathrm{d}) \mathrm{com}-$ pared with those on the HM-WF treatment $(6.3 \mathrm{~L} / \mathrm{d}$; $\mathrm{SE}=0.09 ; P=0.02 ;$ Figure 1a), LM-GF treatment $(2.8$ $\mathrm{L} / \mathrm{d} ; \mathrm{SE}=0.09 ; P<0.001)$, and LM-WF treatment $(2.8 \mathrm{~L} / \mathrm{d} ; \mathrm{SE}=0.09 ; P<0.001)$. Calves on the HMWF treatments $(6.3 \mathrm{~L} / \mathrm{d})$ consumed greater amounts of milk compared with calves on the LM-WF treatment $(2.8 \mathrm{~L} / \mathrm{d}, \mathrm{SE}=0.09 ; P<0.001)$ and LM-GF treatment $(2.8 \mathrm{~L} / \mathrm{d}, \mathrm{SE}=0.09 ; P<0.001)$ during the weaning phase. No difference was detected for milk consumption for calves on the LM-GF treatment $(2.8 \mathrm{~L} / \mathrm{d})$ compared with calves on the LM-WF treatment $(2.8 \mathrm{~L} / \mathrm{d} ; \mathrm{SE}=$ $0.09 ; P=0.71 ;$ Figure 1b). No other milk treatment $\times$ feed treatment interactions were detected for any other measure of intakes during the preweaning, weaning, or postweaning phases (Table 2). 
Parsons et al.: MILK BYPRODUCT-BASED STARTER FEED AND MILK-FEEDING LEVEL

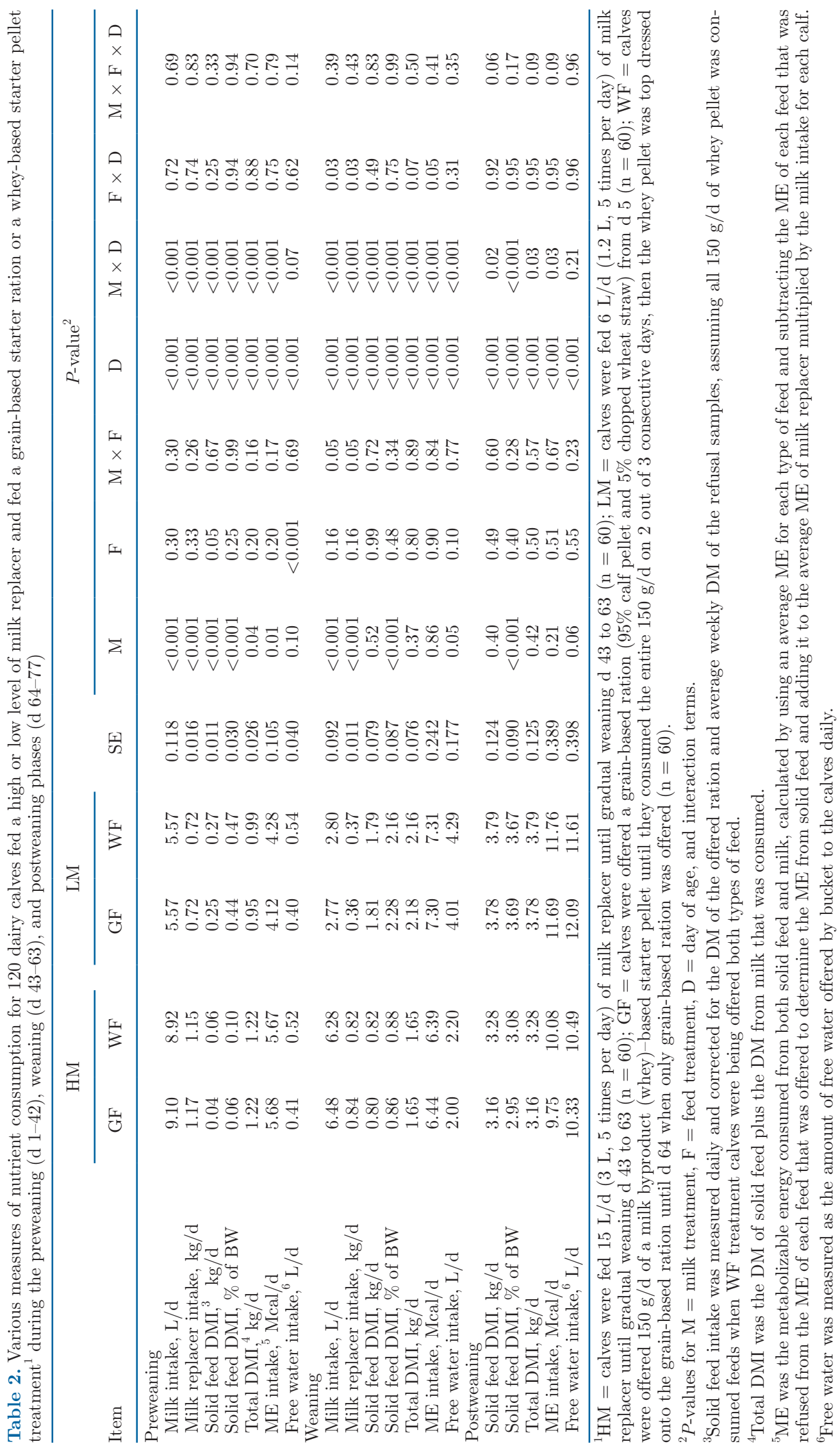



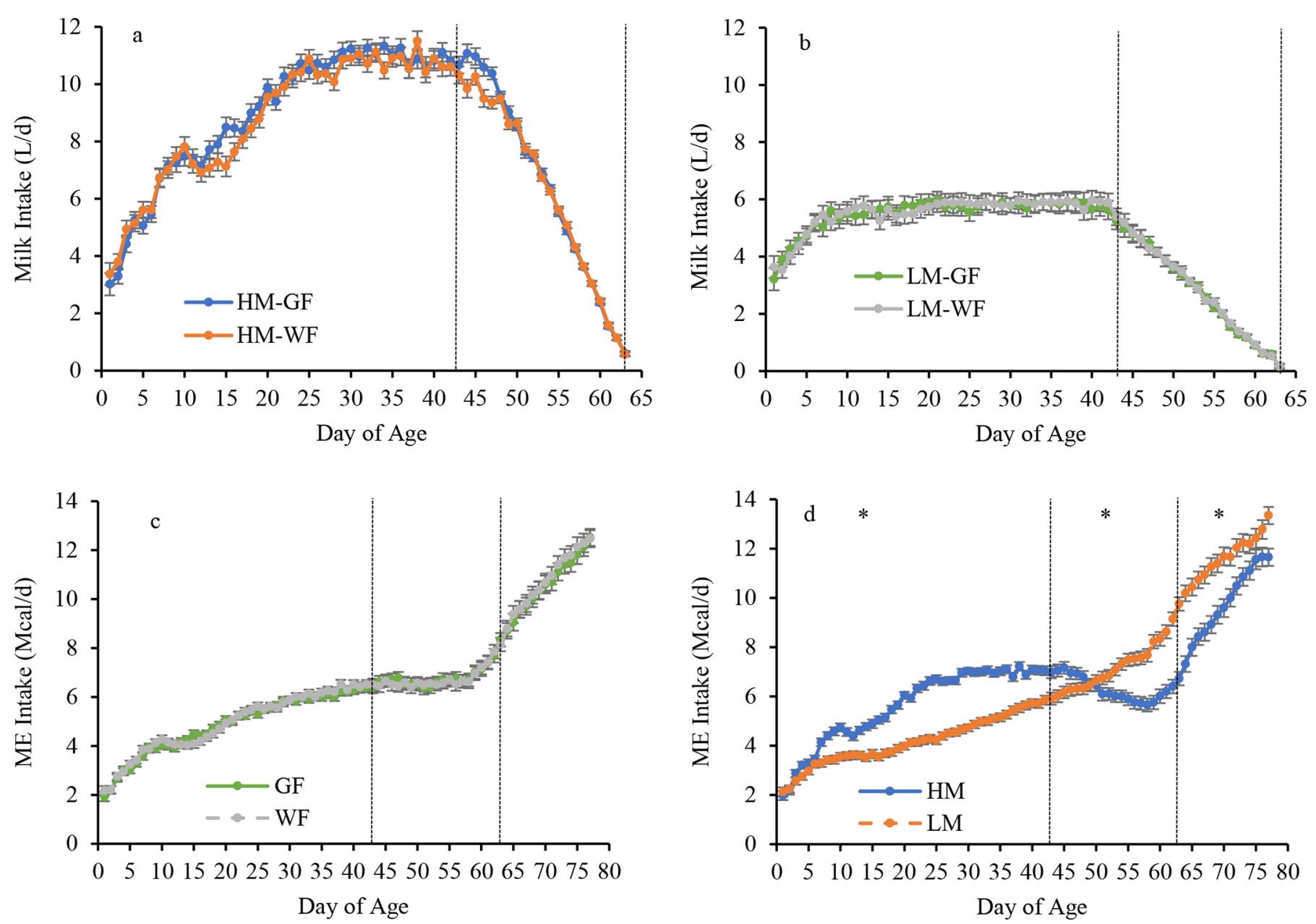

Figure 1. Daily $( \pm \mathrm{SE})$ milk intake (a and b; L/d) and ME intake (c and d; Mcal/d) for calves on 1 of 2 treatments that differed in milk replacer level $[\mathrm{HM}=$ calves were fed $15 \mathrm{~L} / \mathrm{d}(3 \mathrm{~L}, 5 \times / \mathrm{d})$ of milk replacer until gradual weaning commenced at d $43(\mathrm{n}=60) ; \mathrm{LM}=$ calves were fed $6 \mathrm{~L} / \mathrm{d}(1.2 \mathrm{~L}, 5 \times / \mathrm{d})$ of milk replacer until gradual weaning commenced at d $43(\mathrm{n}=60)]$, and for calves on 1 of 2 feed treatments [GF $=$ calves were offered a grain-based ration $(95 \%$ calf pellet and $5 \%$ chopped wheat straw) from d $5(\mathrm{n}=60)$; WF $=$ calves were offered $150 \mathrm{~g} / \mathrm{d}$ of a milk byproduct (whey)-based starter pellet until they consumed the entire $150 \mathrm{~g} / \mathrm{d}$ on 2 out of 3 consecutive days, and then the whey pellet was top dressed onto the grain-based ration until d 64 when only grain-based ration was offered $(\mathrm{n}=60)]$, during the preweaning $(\mathrm{d} 1-42)$, weaning (d 43-63), and postweaning (d 64-77) phases. Vertical lines represent the beginning and end of the weaning phase; * indicates phases where a treatment $\times$ day interaction was detected $(P \leq 0.05)$.

During the preweaning and postweaning phases, calves on the GF and WF treatments consumed similar amounts of ME, regardless of milk treatment (Table 2, Figure 1c). A feed treatment $\times$ day interaction was detected for ME intake in the weaning phase $(P=0.05$; Table 2); however, no day comparisons between feed treatments were significant $(P \geq 0.11)$. Milk treatment $\times$ day interactions were detected for ME intake for the preweaning, weaning, and postweaning phases (Table 2; Figure 1d). Calves on the HM treatment had greater ME intake compared with LM treatment calves on d 4 $(P=0.01)$ and $\mathrm{d} 7$ to $42(P \leq 0.003)$ of the preweaning phase (Figure 1d). During the weaning phase, HM treatment calves consumed greater amounts of $\mathrm{ME}$ compared with LM treatment calves on d 43 to 48 ( $P$ $\leq 0.04)$, and LM treatment calves consumed greater amounts of ME on d 51 to $63(P \leq 0.01)$ compared with HM treatment calves (Figure 1d). The HM treatment calves continued to consume less ME compared with LM treatment calves in the postweaning phase on $\mathrm{d} 64$ to $77(P \leq 0.01$; Figure $1 \mathrm{~d})$.

Calves on the WF treatment reached the transition point to a combination of both feeds (whey pellet top dressed onto grain ration) when they consumed 150 $\mathrm{g} / \mathrm{d}$ (as fed) for 2 out of 3 consecutive days. This feed consumption point was reached similarly $(\mathrm{SE}=1.18 ; P$ $=0.78$ ) at $35.1 \mathrm{~d}$ for WF treatment calves and $34.7 \mathrm{~d}$ for GF treatment calves. Across the preweaning phase, 
calves on the WF treatment consumed greater amounts of solid feed compared with calves on the GF treatment (Table 2; Figure 2a). During the weaning and postweaning phases, WF and GF calves consumed similar amounts of solid feed (Table 2). A milk treatment $x$ day interaction was determined for solid feed DMI in the preweaning, weaning, and postweaning phases (Table 2). During the preweaning phase, LM treatment calves had greater solid feed DMI than HM treatment calves on d 10 to $12(P \leq 0.03)$ and $\mathrm{d} 14$ to $42(P$ $\leq 0.02$; Figure $2 \mathrm{~b}$ ). Calves on the LM treatment had greater solid feed DMI than calves on the HM treatment on d 43 to $63(P<0.001)$ in the weaning phase, and on $\mathrm{d} 64$ to $74(P \leq 0.03)$ and $\mathrm{d} 76$ to $77(P \leq 0.01)$ of the postweaning phase (Supplemental File S2, https: //doi.org/10.5683/SP3/RWCQXV). Milk treatment $\times$ day interactions were also detected for DMI as $\% \mathrm{BW}$ for the preweaning, weaning, and postweaning phases (Table 2). The LM treatment calves, compared with HM treatment calves, had a greater DMI as \% BW on d 17 to $\mathrm{d} 42(P \leq 0.02)$ in the preweaning phase, d 43 to $63(P \leq 0.001)$ in the weaning phase, and $\mathrm{d} 64$ to 77 of the postweaning phase $(P \leq 0.001$; Supplemental File S2). During the preweaning and weaning phases, a milk treatment $x$ day interaction was detected for total DMI (milk and feed DMI combined; Table 2). In the preweaning phase, calves on the HM treatment had greater total DMI than LM treatment calves on $\mathrm{d} 4(P$ $=0.02)$ and $\mathrm{d} 7$ to $38(P \leq 0.02)$. During the weaning phase, calves on the LM treatment compared with the HM treatment had greater total DMI from d 46 to 63 $(P \leq 0.03$; Supplemental File S2). No feed treatment or feed treatment $\times$ day interactions were detected for total DMI or DMI as \% BW during the preweaning, weaning, and postweaning phases (Table 2).

Calves on the WF treatment drank more free water during the preweaning phase and tended to drink more free water in the weaning phase compared with calves on the GF treatment (Table 2; Figure 2c). No effect of feed treatment was detected for free water intake during the postweaning phase (Table 2; Figure 2c). During the preweaning phase, LM treatment calves tended to consume greater amounts of free water compared with HM treatment calves (Table 2; Figure 2d). In the weaning phase, a milk treatment $\times$ day interaction was detected for free water intake, with LM treatment calves consuming greater amounts of free water compared with HM treatment calves on d 43 to $63(P \leq$ 0.02; Figure 2d). During the postweaning phase, LM treatment calves tended to drink more free water than HM treatment calves (Table 2; Supplemental File S1, https://doi.org/10.5683/SP3/RWCQXV).

\section{Rumen Physiological Measurements}

Blood BHB did not differ between feed treatments (Table 3). A milk treatment $\times$ day interaction was detected, with calves on the LM treatment having greater concentrations of blood $\mathrm{BHB}$ on $\mathrm{d} 36(P<$ $0.001)$ and $57(P<0.001)$ than calves on the HM treatment (Supplemental File S3, https://doi.org/10 $.5683 / \mathrm{SP} 3 / \mathrm{RWCQXV}$ ). Rumen fluid $\mathrm{pH}$ did not differ between feed treatments (Figure 3a). A milk treatment $\times$ day interaction was detected for rumen fluid $\mathrm{pH}$, with calves on the HM treatment having greater rumen fluid $\mathrm{pH}$ on $\mathrm{d} 36$ than calves on the LM treatment $(P$ $<0.001$; Figure 3b). On d $70(P=0.02)$ and $\mathrm{d} 77(P$ $=0.002)$, LM treatment calves had greater rumen fluid $\mathrm{pH}$ than HM treatment calves (Figure 3b). No treatment differences were detected for fecal starch for the feed treatments (Table 3) or the milk treatments (Table 3; Supplemental File S3).

A milk treatment $\times$ feed treatment interaction was detected for the proportion of ruminal fluid acetic acid (Table 3). Calves on the HM-GF treatment had a greater proportion of acetic acid compared with calves on the LM-WF treatment $(P=0.007)$. Calves on the HM-WF treatment had a greater proportion of acetic acid compared with calves on the LM-GF treatment $(P$ $=0.007)$ and calves on the LM-WF treatments $(P<$ $0.001)$. No other measures of VFA had a milk treatment $\times$ feed treatment interaction (Table 3). Calves on the LM treatment had a greater proportion of caproic acid than HM treatment calves (Table 3; Supplemental File S4, https://doi.org/10.5683/SP3/RWCQXV). Calves on the GF feed treatment had a greater proportion of isovaleric acid than WF feed treatment calves (Table 3). A feed treatment $\times$ day interaction for proportion of valeric acid was detected, with WF treatment calves having a greater proportion of valeric acid on $\mathrm{d} 36$ and d 57 compared with calves on the GF treatment (Table 4; Supplemental File S4). Irrespective of milk treatment, total VFA concentrations and proportions of propionic acid, butyric acid, isobutyric acid, and caproic acid did not differ between feed treatments over the entire studied period (Table 4).

Total VFA concentration, proportion of propionic acid, butyric acid, isobutyric acid, isovaleric acid, and valeric acid had milk treatment $x$ day interactions (Table 4). Total VFA was greater for calves on the LM treatment compared with the HM treatment on d 36 (Table 4). On d 70, total VFA concentration was greater for calves on the HM treatment compared with the LM treatment (Table 4). Proportion of propionic acid was greater for calves on the LM treatment compared with 

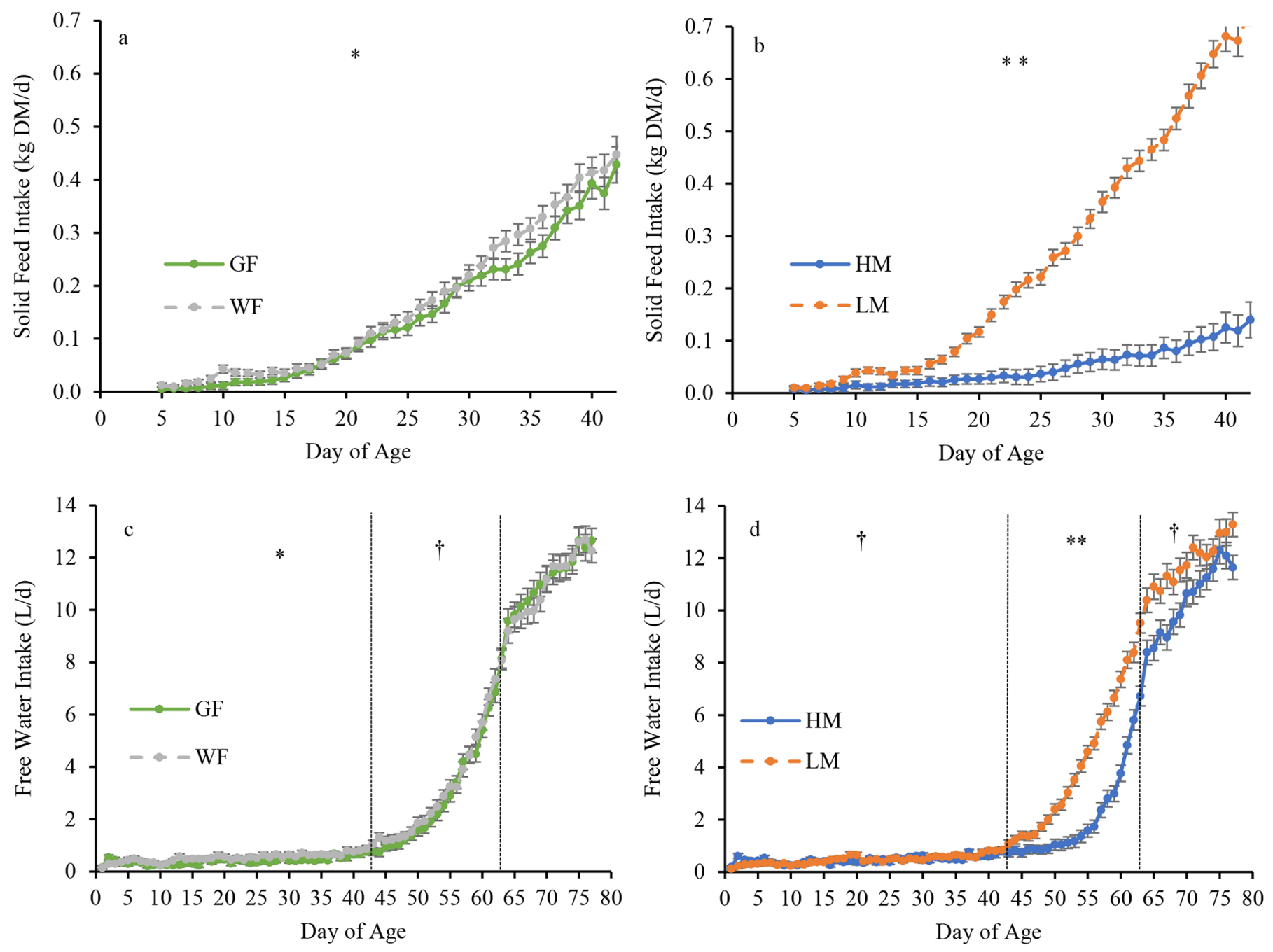

Figure 2. Daily $( \pm \mathrm{SE})$ preweaning (a, b; d 5-42) solid feed intake $(\mathrm{kg}$ of $\mathrm{DM} / \mathrm{d})$, and free water intake (c, d; L/d) for calves on 1 of 2 treatments that differed in milk replacer level $[\mathrm{HM}=$ calves were fed $15 \mathrm{~L} / \mathrm{d}(3 \mathrm{~L}, 5 \times / \mathrm{d})$ of milk replacer until gradual weaning commenced at $\mathrm{d} 43$ $(\mathrm{n}=60) ; \mathrm{LM}=$ calves were fed $6 \mathrm{~L} / \mathrm{d}(1.2 \mathrm{~L}, 5 \times / \mathrm{d})$ of milk replacer until gradual weaning commenced at $\mathrm{d} 43(\mathrm{n}=60)]$, and for calves on 1 of 2 feed treatments [GF $=$ calves were offered a grain-based ration $(95 \%$ calf pellet and $5 \%$ chopped wheat straw) from d $5(\mathrm{n}=60)$; WF $=$ calves were offered $150 \mathrm{~g} / \mathrm{d}$ of a milk byproduct (whey)-based starter pellet until they consumed the entire $150 \mathrm{~g} / \mathrm{d}$ on 2 out of 3 consecutive days, and then the whey pellet was top dressed onto the grain-based ration until d 64 when only grain-based ration was offered $(\mathrm{n}=60)]$, during the preweaning (d 1-42), weaning (d 43-63), and postweaning ( $\mathrm{d}$ 64-77) phases. Vertical lines represent the beginning and end of the weaning phase; * indicates phases for which a treatment effect was detected $(P \leq 0.05)$; $\dagger$ indicates phases for which a tendency for treatment effect was determined $(0.05<P \leq 0.10)$; ** indicates phases for which a treatment $\times$ day interaction was detected $(P \leq 0.05)$.

calves on the HM treatment on d 36 and d 57 (Table 4). Butyric acid was greater for LM treatment calves on d 36 compared with HM treatment calves, but no differences were detected for d 57,70 , and 77 (Table 4). On d 36, HM treatment calves had greater proportions of isobutyric acid and isovaleric acid compared with LM treatment calves (Table 4). On d 57, isovaleric was greater for HM treatment calves compared with LM treatment calves, whereas no difference for isobutryic acid proportions were detected on d 57 (Table 4). Va- leric acid was greater for calves on the LM treatment compared with HM treatment on d 36 and d 57 (Table 4; Supplemental File S4). No differences between milk treatments were detected for any individual VFA proportions on d 70 and $\mathrm{d} 77$.

\section{Growth and Body Measurements}

During the preweaning, weaning, or postweaning phases, ADG did not differ between feed treatments 
Parsons et al.: MILK BYPRODUCT-BASED STARTER FEED AND MILK-FEEDING LEVEL

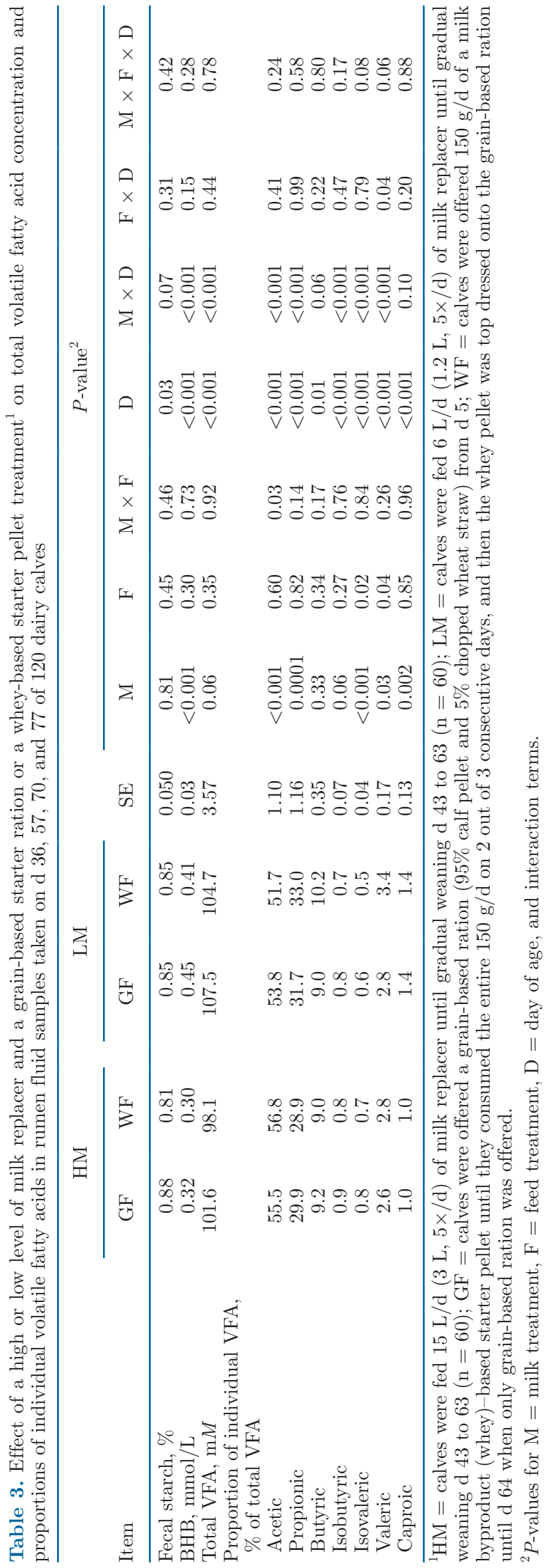

(Table 5). A milk treatment $\times$ week interaction was detected for ADG in the preweaning, weaning, and postweaning phases (Table 5). During the preweaning phase, HM treatment calves had greater ADG compared with LM treatment calves in wk 2 to $6(P<$ 0.001; Supplemental File S5, https://doi.org/10.5683/ SP3/RWCQXV). The LM treatment calves had greater ADG in wk 8 and 9 of the weaning phase, and wk 10 of the postweaning phase compared with HM treatment calves $(P<0.001$; Supplemental File S5). The BW did not differ between feed treatments during the preweaning, weaning, or postweaning phases (Table 5; Supplemental File S5). A milk treatment $\times$ week interaction was detected for BW in the preweaning and weaning phases (Table 5). Calves on the HM treatment, compared with calves on the LM treatment, had greater BW in wk 2 to $6(P<0.001$; Supplemental File S5) during the preweaning phase, and greater $\mathrm{BW}$ in wk 7 to $9(P<0.001)$ during the weaning phase. No milk treatment or treatment $\times$ week interaction was detected for postweaning BW (Table 5).

A milk treatment $\times$ feed treatment interaction was detected for heart girth gain in the preweaning phase (Table 5). During the preweaning phase, there tended to be greater heart girth gain in calves on the HM-GF treatment compared with calves on the HM-WF treatments $(P=0.06)$, calves on the LM-GF treatment $(P$ $<0.001)$, and calves on the LM-WF treatments $(P<$ 0.001). Calves on the HM-WF treatment had greater heart girth gain compared with calves on the LM-GF treatment $(P<0.001)$ and calves on the LM-WF treatment $(P<0.001)$. Calves on the LM-WF treatment tended to have greater heart girth gain than calves on the LM-GF treatment $(P=0.06)$ during the preweaning phase. No other body size measurements for any phases or weeks had a milk treatment $\times$ feed treatment interaction (Table 5).

Calves on the GF and WF treatments had similar heart girth gain during the weaning and postweaning phases (Table 5). Middle girth gain and height gain did not differ between feed treatments during the preweaning, weaning, or postweaning phases (Table 5). Calves on the LM treatment had greater heart girth gain in the weaning and postweaning phases compared with HM treatment calves (Table 5). Middle girth gain had a milk treatment $\times$ week interaction detected in the preweaning and weaning phases (Table 5). During the preweaning phase, HM treatment calves had greater middle girth gain in wk 2 to $4(P \leq 0.04$; Supplemental File S5), compared with LM treatment calves. During the weaning phase, LM treatment calves had greater middle girth gain during wk 7 to $9(P \leq 0.01$; Supplemental File S5) than HM treatment calves. However, in the postweaning phases, middle girth gain was similar 
for both milk treatments (Table 5). The HM treatment calves had greater height gain during the preweaning phase and tended to have a greater height gain during the weaning phase compared with LM treatment calves (Table 5). However, during the postweaning phase, calves on the LM treatment had greater height gain than calves on the HM treatment, regardless of feed treatment (Table 5).

Both feed treatments had similar gain to ME intake ratios during the preweaning $(P=0.14)$, weaning ( $P$ $=0.89)$, and postweaning phases $(P=0.28$; Table 5$)$. In the preweaning phase, a milk treatment $\times$ week interaction was detected $(P<0.001$; Table 5$)$, with HM treatment calves having a greater gain to ME intake ratio than LM treatment calves in wk $2(P<0.001)$ and wk $4(P=0.01$; Supplemental File S5). No treatment differences were detected for ratios of gain to ME intake during the weaning $(P=0.34)$ or postweaning phases for milk treatments $(P=0.16$; Table 5; Supplemental File S6, https://doi.org/10.5683/SP3/RWCQXV).

\section{DISCUSSION}

Despite the average STP levels for each treatment being $\geq 5.5 \mathrm{~g} / \mathrm{dL}$, which is the cut off point for FTPI (Buczinski et al., 2018), 30\% of the trial calves classified as FTPI, which may have explained the high level of disease observed. Calves on this trial experienced a high level of NCD, with $73.3 \%$ of calves being treated for NCD, regardless of treatment. This level is much higher than the $31.7 \%$ recently reported by our group that was conducted at the same facility (Parsons et al., 2020 ) and the $21.4 \%$ reported for digestive issues in North America (Urie et al., 2018).

\section{Nutrient Consumption}

In agreeance with previous work (Appleby et al., 2001; Jasper and Weary, 2002), when offered more milk replacer, as in the HM treatment, calves consumed more milk for the majority of the preweaning phase (d $4-5$ and d 7-42). Consistent with previous work when feeding by AMF systems, calves consumed a lower amount of milk than their allowance in the preweaning phase, regardless of milk treatment (Rosenberger et al., 2017; Rosadiuk et al., 2021). Because GF and WF treatment calves consumed similar levels of milk in the preweaning phase, the different types of feed had no effect on preweaning milk consumption. During the weaning phase, the milk treatment $\times$ feed treatment results suggested neither feed treatment affected the milk consumption for calves assigned to the LM treatment in the weaning phase. However, the feed treatment may have affected milk consumption for calves on the HM treatment, as calves on the HM-GF treatment consumed greater amounts of milk in the weaning phase than calves on the HM-WF treatments.
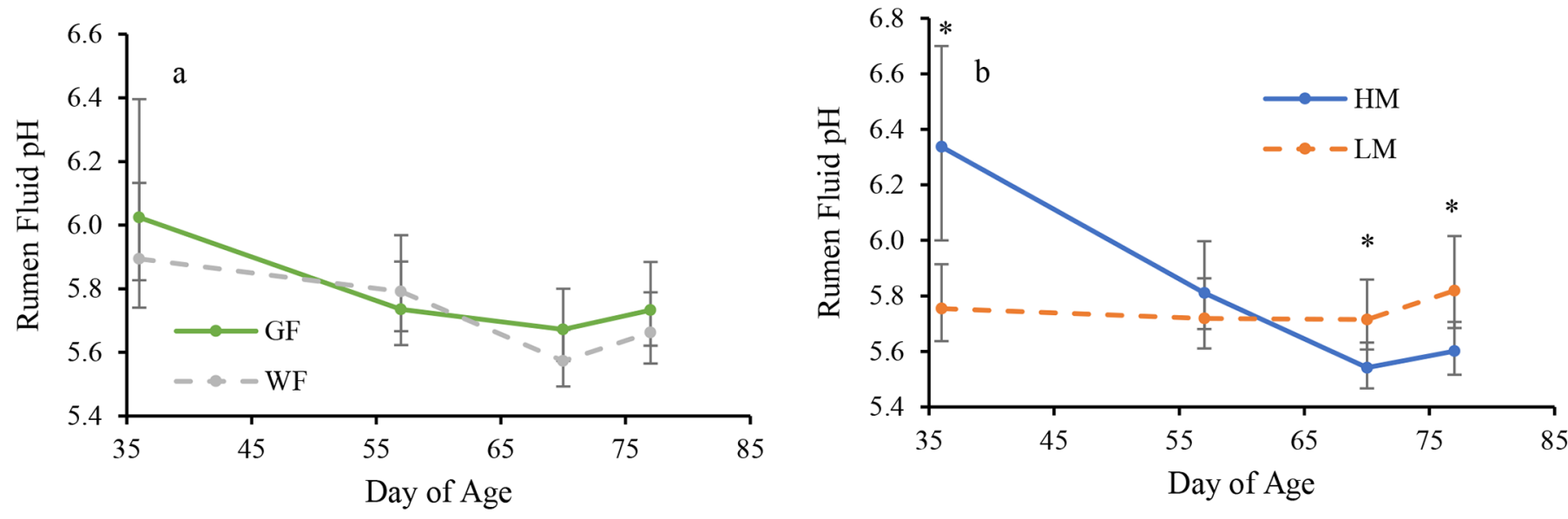

Figure 3. Rumen fluid $\mathrm{pH}$ (back-transformed $\mathrm{H}^{+}$ion concentration $\pm 95 \% \mathrm{CI}$ ) for calves on 1 of 2 treatments that differed in milk replacer level $[\mathrm{HM}=$ calves were fed $15 \mathrm{~L} / \mathrm{d}(3 \mathrm{~L}, 5 \times / \mathrm{d})$ of milk replacer until gradual weaning from d 43 to $63(\mathrm{n}=60) ; \mathrm{LM}=$ calves were fed $6 \mathrm{~L} / \mathrm{d}$ $(1.2 \mathrm{~L}, 5 \times / \mathrm{d})$ of milk replacer until gradual weaning from d 43 to $63(\mathrm{n}=60)]$, and for calves on 1 of 2 feed treatments [GF $=$ calves were offered a grain-based ration (95\% calf pellet and $5 \%$ chopped wheat straw) from d $5(\mathrm{n}=60)$; WF $=$ calves were offered $150 \mathrm{~g} / \mathrm{d}$ of a milk byproduct (whey)-based starter pellet until they consumed the entire $150 \mathrm{~g} / \mathrm{d}$ on 2 out of 3 consecutive days, and then the whey pellet was top dressed onto the grain-based ration until d 64 when only grain-based ration was offered $(\mathrm{n}=60)]$, on $\mathrm{d} 36,57,70$, and 77 . * indicates significant differences $(P \leq 0.05)$ between treatments at individual days. 
Despite both GF and WF treatment calves consuming $150 \mathrm{~g} / \mathrm{d}$ for 2 out of 3 consecutive days at a similar age, calves on the WF treatment may have been encouraged to consume greater amounts of solid feed early in life. Terré et al. (2016) previously reported an increase in feed consumption from d 11 to 15 when fed a similar milk byproduct-based pellet. The current study was the first to report an increase in feed consumption across the entire preweaning phase. This intake advantage disappeared in the weaning and postweaning phases, suggesting the need for further research on ways to supplement the grain ration with the milk byproduct-based feed.

Interestingly, feed consumption did not begin to differ until d 10 for LM and HM treatment calves, indicating calves would not consume feed in measurable amounts early in life (Jasper and Weary, 2002), and thus must consume milk to meet energy requirements. Researchers have previously demonstrated that calves fed high levels of milk will eventually catch up to restricted fed calves postweaning (Jasper and Weary, 2002; Hill et al., 2016; Rosenberger et al., 2017). This was not the

Table 4. Effect of a high or low level of milk replacer and a grain-based starter ration or a whey-based starter pellet treatment ${ }^{1}$ on total volatile fatty acid concentration and proportions of individual volatile fatty acids in rumen fluid samples on d 36, 57, 70, and 77

\begin{tabular}{|c|c|c|c|c|c|c|c|}
\hline \multirow[b]{2}{*}{ Item } & \multicolumn{2}{|c|}{ HM } & \multicolumn{2}{|c|}{$\mathrm{LM}$} & \multirow[b]{2}{*}{ SE } & \multicolumn{2}{|c|}{$P$-value ${ }^{2}$} \\
\hline & GF & WF & GF & WF & & $\mathrm{M}$ & $\mathrm{F}$ \\
\hline \multicolumn{8}{|l|}{ Day 36} \\
\hline Total VFA $(\mathrm{m} M)$ & 62.7 & 54.0 & 98.9 & 101.0 & 6.54 & $<0.001$ & 0.61 \\
\hline \multicolumn{8}{|c|}{ Proportion of individual VFA, $\%$ of total VFA } \\
\hline Acetic & 65.0 & 66.8 & 56.9 & 52.1 & 1.89 & $<0.001$ & 0.40 \\
\hline Propionic & 23.2 & 20.8 & 30.2 & 32.8 & 1.59 & $<0.001$ & 0.90 \\
\hline Butyric & 7.3 & 7.4 & 8.8 & 10.0 & 0.80 & 0.009 & 0.43 \\
\hline Isobutyric & 1.3 & 1.2 & 1.0 & 0.8 & 0.10 & $<0.001$ & 0.28 \\
\hline Isovaleric & 1.5 & 1.5 & 0.8 & 0.6 & 0.11 & $<0.001$ & 0.36 \\
\hline Valeric & 1.3 & 1.7 & 2.2 & 3.2 & 0.25 & $<0.001$ & 0.002 \\
\hline Caproic & 0.4 & 0.5 & 0.6 & 0.7 & 0.12 & 0.03 & 0.46 \\
\hline \multicolumn{8}{|l|}{ Day 57} \\
\hline Total VFA $(\mathrm{m} M)$ & 109.1 & 99.4 & 116.6 & 106.8 & 5.40 & 0.15 & 0.06 \\
\hline \multicolumn{8}{|c|}{ Proportion of individual VFA, \% of total VFA } \\
\hline Acetic & 55.2 & 53.9 & 52.9 & 51.4 & 1.38 & 0.04 & 0.21 \\
\hline Propionic & 30.0 & 29.5 & 32.4 & 33.0 & 1.52 & 0.02 & 0.97 \\
\hline Butyric & 10.5 & 11.3 & 9.0 & 12.1 & 1.38 & 0.77 & 0.15 \\
\hline Isobutyric & 0.9 & 0.7 & 0.6 & 0.7 & 0.09 & 0.13 & 0.29 \\
\hline Isovaleric & 0.8 & 0.5 & 0.4 & 0.4 & 0.07 & 0.03 & 0.03 \\
\hline Valeric & 2.2 & 3.2 & 3.2 & 3.5 & 0.25 & $<0.001$ & 0.007 \\
\hline Caproic & 0.8 & 0.8 & 1.5 & 1.9 & 0.30 & 0.002 & 0.42 \\
\hline \multicolumn{8}{|l|}{ Day 70} \\
\hline Total VFA $(\mathrm{m} M)$ & 121.6 & 125.9 & 110.4 & 108.3 & 5.50 & 0.002 & 0.91 \\
\hline \multicolumn{8}{|c|}{ Proportion of individual VFA, $\%$ of total VFA } \\
\hline Acetic & 49.7 & 52.3 & 52.1 & 50.8 & 1.29 & 0.64 & 0.52 \\
\hline Propionic & 33.6 & 33.5 & 33.1 & 33.5 & 1.50 & 0.84 & 0.89 \\
\hline Butyric & 9.8 & 9.0 & 8.8 & 9.6 & 0.48 & 0.67 & 0.87 \\
\hline Isobutyric & 0.7 & 0.6 & 0.7 & 0.6 & 0.08 & 0.36 & 0.21 \\
\hline Isovaleric & 0.4 & 0.4 & 0.4 & 0.4 & 0.04 & 0.19 & 0.06 \\
\hline Valeric & 4.0 & 3.4 & 2.9 & 3.5 & 0.31 & 0.10 & 0.92 \\
\hline Caproic & 1.6 & 1.4 & 1.9 & 1.5 & 0.20 & 0.35 & 0.14 \\
\hline \multicolumn{8}{|l|}{ Day 77} \\
\hline Total VFA $(\mathrm{m} M)$ & 112.9 & 113.3 & 104.0 & 102.9 & 6.95 & 0.15 & 0.96 \\
\hline \multicolumn{8}{|c|}{ Proportion of individual VFA, $\%$ of total VFA } \\
\hline Acetic & 52.2 & 54.2 & 53.3 & 52.5 & 1.50 & 0.79 & 0.65 \\
\hline Propionic & 32.8 & 31.9 & 31.1 & 32.6 & 1.72 & 0.75 & 0.83 \\
\hline Butyric & 9.2 & 8.4 & 9.5 & 9.0 & 0.61 & 0.45 & 0.26 \\
\hline Isobutyric & 0.8 & 0.8 & 0.8 & 0.8 & 0.10 & 0.92 & 0.73 \\
\hline Isovaleric & 0.6 & 0.6 & 0.7 & 0.6 & 0.10 & 0.60 & 0.47 \\
\hline Valeric & 3.1 & 2.8 & 3.0 & 3.2 & 0.31 & 0.62 & 0.90 \\
\hline Caproic & 1.2 & 1.4 & 1.5 & 1.5 & 0.21 & 0.26 & 0.76 \\
\hline
\end{tabular}

${ }^{1} \mathrm{HM}=$ calves were fed $15 \mathrm{~L} / \mathrm{d}(3 \mathrm{~L}, 5 \times / \mathrm{d})$ of milk replacer until gradual weaning d 43 to $63(\mathrm{n}=60) ; \mathrm{LM}=$ calves were fed $6 \mathrm{~L} / \mathrm{d}(1.2 \mathrm{~L}, 5 \times / \mathrm{d})$ of milk replacer until gradual weaning d 43 to $63(\mathrm{n}=60) ; \mathrm{GF}=$ calves were offered a grain-based ration $(95 \%$ calf pellet and $5 \%$ chopped wheat straw) from d 5; WF = calves were offered $150 \mathrm{~g} / \mathrm{d}$ of a milk byproduct (whey)-based starter pellet until they consumed the entire 150 $\mathrm{g} / \mathrm{d}$ on 2 out of 3 consecutive days, and then the whey pellet was top dressed onto the grain-based ration until d 64 when only grain-based ration was offered.

${ }^{2} P$-values for day-by-day comparisons for $\mathrm{M}=$ milk treatment and $\mathrm{F}=$ feed treatment. 
Parsons et al.: MILK BYPRODUCT-BASED STARTER FEED AND MILK-FEEDING LEVEL

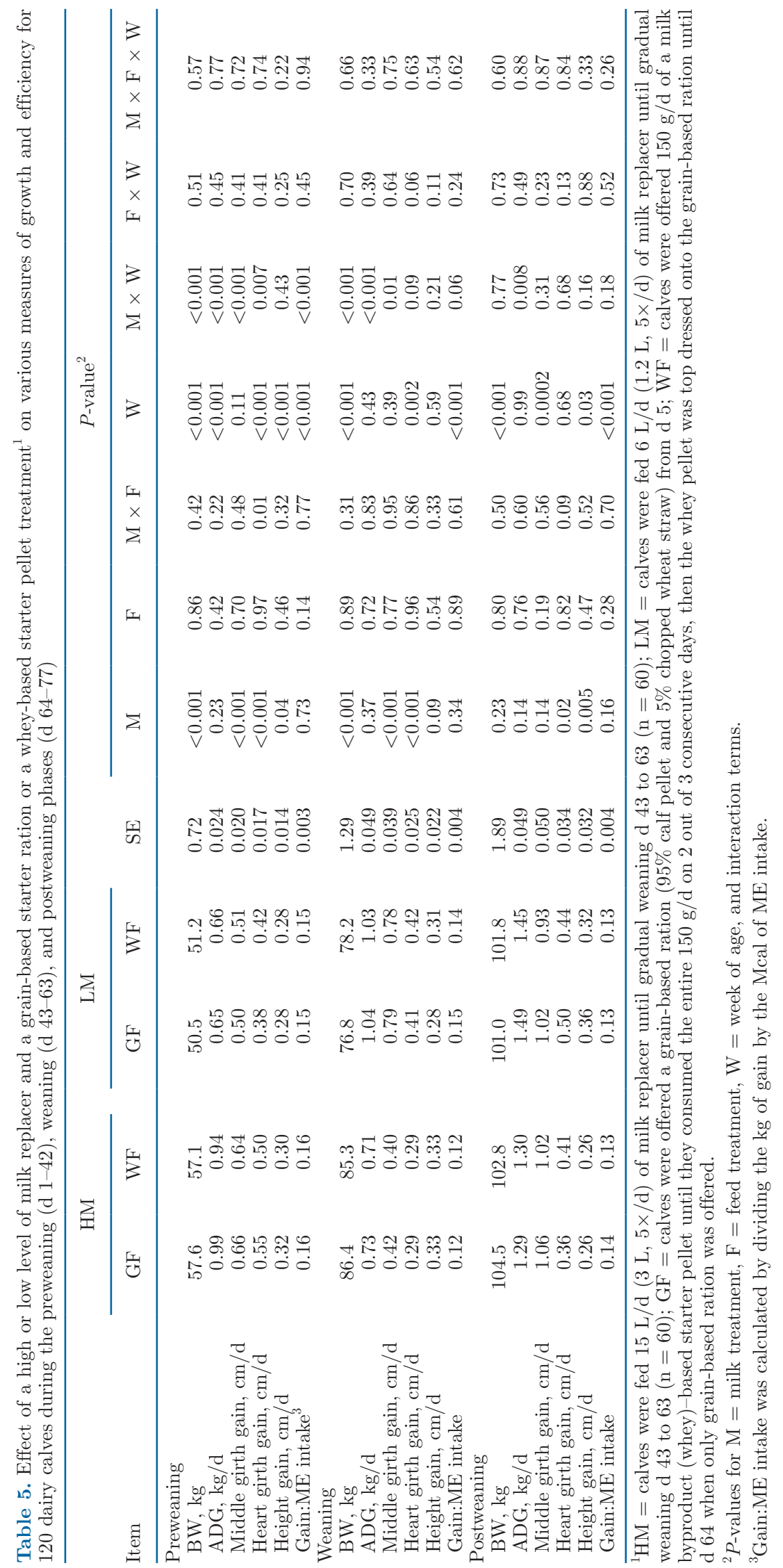


case in the current trial, as LM calves maintained the DMI advantage over HM calves postweaning. It is possible that the way calves were weaned off milk was not optimal for the HM treatment calves, as it may not have stimulated enough feed intake - for it appears that calves on the HM treatment (Figure 1a) began weaning later than LM treatment calves (Figure 1b), which was not the intent. Based on the average milk intake, HM treatment calves did not experience a reduction in their milk until d 51; therefore, the actual weaning for HM calves was only $13 \mathrm{~d}$ long. Therefore, it is possible that the HM calves did not experience a large enough milk reduction to stimulate feed intake early enough to catch up to the LM treatment calves in this trial.

It was not surprising that GF and WF treatments consumed similar amounts of ME during the trial, as milk intake was similar in the preweaning and weaning phases, whereas feed intake was only $0.02 \mathrm{~kg} / \mathrm{d}$ greater for WF compared with GF calves in the preweaning phase. Furthermore, as HM treatment calves drank more milk, they had greater ME consumption for the majority of the preweaning phase compared with LM treatment calves, indicating that feeding low levels of milk may stimulate DMI, but DMI cannot compensate for the ME consumed by higher levels of milk (Nielsen et al., 2008; Sweeney et al., 2010). During the weaning phase, there was a point in time when ME intake for HM calves became lower than ME intake for LM calves due to DMI of HM calves lagging behind, as previously reported by Rosadiuk et al. (2021). However, contrary to HM calves in the present trial who did not reach LM calves' ME intake levels postweaning, Rosadiuk et al. (2021) detected no ME intake differences a week postweaning.

Solid feed intake and water intake are closely linked (Eckert et al., 2015; Wickramasinghe et al., 2019; Parsons et al., 2020). The results of this study support this concept, with LM treatment calves having greater DMI and greater water consumption for most of the study. Additionally, the WF calves consumed greater amounts of free water in the preweaning phase, as their solid feed DMI was also greater compared with the GF calves. However, WF calves tended to also have greater free water intake than GF calves in the weaning phase, when no differences in DMI were detected. It is possible the WF calves consumed more water due to an osmotic imbalance. Previous work suggests that calves fed high levels of milk and increased total solids in reconstituted milk replacer may increase water intake to maintain osmolality (Guindon et al., 2015). This may be caused by an electrolyte imbalance or the accumulation of lactose in the gastrointestinal tract (Dratwa-Chałupnik et al., 2012). As the whey-based feed (as in the WF treatment) contained lactose and greater amounts of minerals compared with the grain-based ration (as in the GF treatment), the WF treatment calves may have consumed more water to compensate for this and maintain osmotic balance; this is an area that warrants further research.

\section{Rumen Physiological Measurements}

The transition from a nonruminant to a functioning ruminant depends on starter intake and fermentation. The DMI advantage for the WF treatment in the preweaning phase was not enough to drive a change in blood BHB compared with GF treatment calves. When LM calves were experiencing an initial DMI advantage over HM calves, their blood BHB concentrations were also greater. However, because no differences in BHB were detected postweaning, it can be suggested that the HM treatment calves consumed enough DMI to support equal rumen development. Overall, regardless of both milk and feed treatments, all calves reached levels that indicated sufficient solid feed intake to promote rumen development, based on blood BHB, by the end of the trial. Although no treatment effects were detected for fecal starch percentage, a low concentration was reported in the present trial, suggesting adequate starch digestion and absorption in the hindgut for all treatments (Rosadiuk et al., 2021).

As rumen fluid $\mathrm{pH}$ can be affected by the fermentation of feed, it was not surprising that rumen fluid $\mathrm{pH}$ was similar for calves on the feed treatments, as they had similar feed consumption for most of the trial. Rumen fluid $\mathrm{pH}$ on $\mathrm{d} 36$ was higher for HM calves than LM calves, likely due to HM calves not consuming as much solid feed, and thus not lowering the $\mathrm{pH}$ from fermentation as much as LM calves. As HM treatment calves increased their feed consumption postweaning, it is possible their $\mathrm{pH}$ was lower than LM treatment calves on $\mathrm{d} 70$ and 77 , as their rumen was not adequately adapted to handle the increase in feed consumption and subsequent proton production from fermentation (Laarman and Oba, 2011).

Although WF treatment calves had greater solid feed intake in the preweaning phase, it was likely not large enough to drive major rumen development improvements, as indicated by no difference in total VFA concentrations or butyric acid proportions in rumen fluid samples. The WF treatment feed, being high in milk byproduct ingredients, specifically whey, may have resulted in greater valeric acid production for those calves while they were consuming the whey-based feed before the d 70 and 77 fluid samples (Fisher, 1983; Górka et al., 2011). Alternatively, GF calves had a greater 
proportion of isovaleric acid, which is a growth factor for cellulolytic bacteria that digests forages (Anderson et al., 1987).

Calves on the HM-GF treatment had greater acetic acid production than calves on the LM-WF treatment. Consumed forage promotes acetate production (Imani et al., 2017); this may be due to the grain-based ration (as in the GF treatment) having forage in the form of $5 \%$ chopped straw and the HM-GF calves consuming greater amounts of forage. Calves on the HM-WF treatment had greater acetic acid proportion in fluid samples than calves on the LM-GF and LM-WF treatment, likely at the expense of another VFA. Additionally, although not measured, the LM-GF and LM-WF treatment calves may have been sorting against the $5 \%$ forage component of their diets more so compared with HM-GF and HM-WF treatment calves. Total VFA was expected to be greater for LM calves due to their greater feed consumption on d 36; however, HM calves had greater total VFA on d 70, despite having lower feed consumption. Similar results were reported by Khan et al. (2007), who concluded that before dropping milk down, calves fed less milk (10\% BW) had increased total VFA, but calves fed more milk (20\% BW) had increased total VFA at weaning and postweaning. This may suggest calves can be fed high levels of milk without compromising rumen development. However, this also may be a result of calves fed greater levels of milk having a drastic increase in DMI once weaned, causing a sudden increase in VFA production, and if not developed well, the rumen may not absorb VFA as efficiently. However, as described previously, the milk treatments had similar BHB measurements on d 70 , and their absorption of butyrate was likely similar. Overall, on d 70 and d 77, no individual VFA proportions differed between the 2 milk treatments, or the 2 feed treatments, concluding similar rumen development within 1 to 2 wk postweaning.

\section{Growth and Body Measurements}

Heart girth gain was greater for calves on the HMGF treatment compared with the HM-WF treatment calves, which was surprising as there was no milk treatment $\times$ feed treatment interaction detected for $\mathrm{ME}$ intake in the preweaning phase. It was not surprising that calves on the WF or GF treatment and the HM treatment had greater heart girth gain in the preweaning phase compared with calves on the LM treatment, due to increased milk consumption. However, LM-WF treatment calves tended to have a greater heart girth gain than LM-GF treatment calves in the preweaning phase, indicating that calves on the LM treatment and fed the WF feed treatment may experience improved structural growth. Terré et al. (2016) fed a low level of milk ( $5 \mathrm{~L} / \mathrm{d}, 12.5 \% \mathrm{DM})$ to calves that were fed either a milk byproduct-based pellet or a grain-based pellet, similar to the LM-WF and LM-GF treatment in the present trial, and they concluded that calves fed the milk byproduct-based starter pellet had improved ADG during d 14 to 21, with greater feed intake d 11 to 15 compared with calves fed a conventional pellet. The present results, and those from Terré et al. (2016), suggest that increased feed intake when fed the WF treatment may improve structural growth when fed a low level of milk in the preweaning phase. No other growth or structural size differences were detected for calves fed either feed treatment, regardless of milk level, for any other phase, suggesting the increase in DMI for the WF treatment in the preweaning phase was not large enough to effect prolonged growth. As ME intakes and ADG were similar between feed treatments, ratios of gain to ME intake were not different, suggesting similar efficiency of growth.

Providing increased milk early in life, as we observed with the HM treatment, results in increased ADG and BW in the preweaning phase (Appleby et al., 2001; Jasper and Weary, 2002; Rosenberger et al., 2017). However, LM calves had greater ADG in the second and third week of weaning, and first week postweaning, likely driven by LM calves consuming greater ME intake as weaning progressed. Although this is a common challenge observed when weaning off high levels of milk (Jasper and Weary, 2002; Rosenberger et al., 2017; Parsons et al., 2020), it is interesting to note that a growth slump was still observed despite the planned, steady, and gradual weaning program over 3 wk. As described previously, this is likely due to HM treatment calves only experiencing weaning for $13 \mathrm{~d}$ compared with the designed $21 \mathrm{~d}$, which is shorter than the 14 to $21 \mathrm{~d}$ weaning period that Hill et al. (2012) recommends to avoid ADG reductions. Thus, HM treatment calves may have benefited from longer weaning or later weaning, allowing more time to get onto enough solid feed and maintain growth (Eckert et al., 2015). As observed in the present trial, calves fed varying levels of milk or milk replacer have been previously reported to have similar postweaning BW, indicating that proper weaning continues to be an issue with maintaining growth advantages (Cowles et al., 2006; Hill et al., 2016).

As structural growth and BW are closely linked (Heinrichs et al., 1992), the ADG differences are likely the result of detected structural growth differences. The present gain-to-ME intake ratio results for milk treatments are consistent with previous work that suggests feed efficiency of calves fed high milk levels can be negatively affected by reductions in milk during weaning (Scoley et al., 2019) or may be lower when 
compared with calves fed low levels of milk $(5 \mathrm{~L} / \mathrm{d})$ postweaning (Rosadiuk et al., 2021).

\section{CONCLUSIONS}

The results in this study suggested the milk byproduct-based pellet treatment (as in the WF treatment) may encourage greater feed and water consumption early in life during the preweaning phase compared with a traditional starter ration, no matter the level of milk fed. However, as both feed treatments (WF and GF) resulted in similar growth and final markers of rumen development, the WF treatment did not likely affect long-term development. Irrespective of feed treatment, calves on the LM milk treatment had greater feed consumption for most days on trial, but lagged behind in BW compared with HM milk treatment calves during the preweaning and weaning phases. These results are in agreement with the concept that calves should be fed high levels of milk to support growth early in life, and these calves are capable of achieving enough solid feed intake to support similar postweaning rumen development compared with calves that are fed a low level of milk. Additionally, when feeding a low level of milk, calves fed the WF compared with the GF treatment may experience a structural growth benefit, indicated by a tendency for greater heart girth gain, although no other performance markers were affected by the WF treatment.

\section{ACKNOWLEDGMENTS}

The authors thank all of the staff at the University of Guelph, Elora Research Station-Ontario Dairy Research Centre (Elora, Ontario, Canada), with a special thanks to Laura Wright for their assistance in facilitating this research project. The authors also thank Kaitlyn Dancy, Meagan King, Brooke McNeil, Clayton McWilliams, and Andrea Bajus of the University of Guelph (Guelph, ON, Canada) for their assistance with data collection and organization; and Tess Altvater-Hughes and Shannon Cartwright of the University of Guelph (Guelph, ON, Canada) for their assistance with data collection for STP concentrations. This research was funded by a Natural Sciences and Engineering Research Council of Canada (NSERC; Ottawa, ON, Canada) Engage Grant with Grand Valley Fortifiers (Cambridge, ON, Canada). Further funding and research support was received through the Ontario Agri-Food Innovation Alliance Research Program of the University of Guelph and the Ontario Ministry of Agriculture, Food and Rural Affairs (OMAFRA; Guelph, ON, Canada). The authors have not stated any conflicts of interest.

\section{REFERENCES}

Anderson, K. L., T. G. Nagaraja, and J. L. Morrill. 1987. Ruminal metabolic development in calves weaned conventionally or early. J. Dairy Sci. 70:1000-1005. https://doi.org/10.3168/jds.S0022 $-0302(87) 80105-4$.

AOAC International. 1995. Official Methods of Analysis. Vol. I. 16th ed. AOAC International.

AOAC International. 2000. Official Methods of Analysis. Vol. I. 17 th ed. AOAC International.

Appleby, M. C., D. M. Weary, and B. Chua. 2001. Performance and feeding behaviour of calves on ad libitum milk from artificial teats. Appl. Anim. Behav. Sci. 74:191-201. https://doi.org/10.1016/ S0168-1591(01)00171-X.

Benschop, D. L., and J. P. Cant. 2009. Developmental changes in clearance of intravenous doses of glucose, acetate and $\beta$-hydroxybutyrate from plasma of calves. Livest. Sci. 122:177-185. https://doi.org/10 .1016/j.livsci.2008.08.011.

Buczinski, S., E. Gicquel, G. Fecteau, Y. Takwoingi, M. Chigerwe, and J. M. Vandeweerd. 2018. Systematic review and meta-analysis of diagnostic accuracy of serum refractometry and brix refractometry for the diagnosis of inadequate transfer of passive immunity in calves. J. Vet. Intern. Med. 32:474-483. https://doi.org/10.1111/ jvim.14893.

Buczinski, S., and J. M. Vandeweerd. 2016. Diagnostic accuracy of refractometry for assessing bovine colostrum quality: A systematic review and meta-analysis. J. Dairy Sci. 99:7381-7394. https://doi .org/10.3168/jds.2016-10955.

Budzynska, M., and D. M. Weary. 2008. Weaning distress in dairy calves: Effects of alternative weaning procedures. Appl. Anim. Behav. Sci. 112:33-39. https://doi.org/10.1016/j.applanim.2007.08 .004 .

Canadian Council of Animal Care. 2009. Guidelines on the care and use of farm animals in research, teaching and testing. Canadian Council of Animal Care.

Cowles, K. E., R. A. White, N. L. Whitehouse, and P. S. Erickson. 2006. Growth characteristics of calves fed an intensified milk replacer regimen with additional lactoferrin. J. Dairy Sci. 89:48354845. https://doi.org/10.3168/jds.S0022-0302(06)72532-2.

de Passillé, A. M. B., and J. Rushen. 2006. Calves' behaviour during nursing is affected by feeding motivation and milk availability. Appl. Anim. Behav. Sci. 101:264-275. https://doi.org/10.1016/j .applanim.2006.02.007.

Deelen, S. M., K. E. Leslie, M. A. Steele, E. Eckert, H. E. Brown, and T. J. DeVries. 2016. Validation of a calf-side $\beta$-hydroxybutyrate test and its utility for estimation of starter intake in dairy calves around weaning. J. Dairy Sci. 99:7624-7633. https://doi.org/10 .3168/jds.2016-11097.

DePeters, E. J., L. J. Fisher, and J. L. Stone. 1986. Effect of adding dried whey to starter diet of early and late weaned calves. J. Dairy Sci. 69:181-186. https://doi.org/10.3168/jds.S0022-0302(86)80384 -8 .

Drackley, J. K. 2008. Calf nutrition from birth to breeding. Vet. Clin. North Am. Food Anim. Pract. 24:55-86. https://doi.org/10.1016/ j.cvfa.2008.01.001.

Dratwa-Chałupnik, A., A. Herosimczyk, A. Lepczynśki, and W. F. Skrzypczak. 2012. Calves with diarrhea and a water-electrolyte balance. Med. Weter. 68:5-8.

Eckert, E., H. E. Brown, K. E. Leslie, T. J. DeVries, and M. A. Steele. 2015. Weaning age affects growth, feed intake, gastrointestinal development, and behavior in Holstein calves fed an elevated plane of nutrition during the preweaning stage. J. Dairy Sci. 98:6315-6326. https://doi.org/10.3168/jds.2014-9062.

Fisher, L. J. 1983. Evaluation of concentrated whey and canola meal mixture as a substitute for grain in the rations of calves. Can. J. Anim. Sci. 63:587-593. https://doi.org/10.4141/cjas83-066.

Fisher, L.J., and W.T. Buckley. 1985. Effect of feeding a concentrated whey-canola meal mixture as the major component of starter rations for calves. Can. J. Anim. Sci. 65:683-691.

Górka, P., Z. M. Kowalski, P. Pietrzak, A. Kotunia, W. Jagusiak, and R. Zabielski. 2011. Is rumen development in newborn calves af- 
fected by different liquid feeds and small intestine development? J. Dairy Sci. 94:3002-3013. https://doi.org/10.3168/jds.2010-3499.

Guindon, N. E., N. T. Antaya, R. G. Cabral, N. L. Whitehouse, T. J. Earleywine, and P. S. Erickson. 2015. Effects of human visitation on calf growth and performance of calves fed different milk replacer feeding levels. J. Dairy Sci. 98:8952-8961. https://doi.org/ 10.3168/jds.2015-9759.

Heinrichs, A. J., G. W. Rogers, and J. B. Cooper. 1992. Predicting body weight and wither height in Holstein heifers using body measurements. J. Dairy Sci. 75:3576-3581. https://doi.org/10.3168/ jds.S0022-0302(92)78134-X.

Hill, T. M., H. G. Bateman II, J. M. Aldrich, and R. L. Schlotterbeck. 2010. Effect of milk replacer program on digestion of nutrients in dairy calves. J. Dairy Sci. 93:1105-1115. https://doi.org/10.3168/ jds.2009-2458.

Hill, T. M., H. G. Bateman II, J. M. Aldrich, and R. L. Schlotterbeck. 2012. Methods of reducing milk replacer to prepare dairy calves for weaning when large amounts of milk replacer have been fed. Prof. Anim. Sci. 28:332-337. https://doi.org/10.15232/S1080 -7446(15)30364-8.

Hill, T. M., J. D. Quigley, H. G. Bateman II, F. X. Suarez-Mena, T. S. Dennis, and R. L. Schlotterbeck. 2016. Effect of milk replacer program on calf performance and digestion of nutrients in dairy calves to 4 months of age. J. Dairy Sci. 99:8103-8110. https://doi .org/10.3168/jds.2016-11239.

Hintze, J. 2008. Power Analysis and Sample Size System (PASS) 2008. NCSS, LLC

Imani, M., M. Mirzaei, B. Baghbanzadeh-Nobari, and M. H. Ghaffari. 2017. Effects of forage provision to dairy calves on growth performance and rumen fermentation: A meta-analysis and metaregression. J. Dairy Sci. 100:1136-1150. https://doi.org/10.3168/ jds.2016-11561.

Jasper, J., and D. M. Weary. 2002. Effects of ad libitum milk intake on dairy calves. J. Dairy Sci. 85:3054-3058. https://doi.org/10.3168/ jds.S0022-0302(02)74391-9.

Jung, J., and L. Lidfors. 2001. Effects of amount of milk, milk flow and access to a rubber teat on cross-sucking and non-nutritive sucking in dairy calves. Appl. Anim. Behav. Sci. 72:201-213. https://doi .org/10.1016/S0168-1591(01)00110-1.

Khan, M. A., A. Bach, D. M. Weary, and M. A. G. von Keyserlingk. 2016. Invited review: Transitioning from milk to solid feed in dairy heifers. J. Dairy Sci. 99:885-902. https://doi.org/10.3168/jds.2015 $-9975$.

Khan, M. A., H. J. Lee, W. S. Lee, H. S. Kim, K. S. Ki, T. Y. Hur, G. H. Suh, S. J. Kang, and Y. J. Choi. 2007. Structural growth, rumen development, and metabolic and immune responses of Holstein male calves fed milk through step-down and conventional methods. J. Dairy Sci. 90:3376-3387. https://doi.org/10.3168/jds .2007-0104

Khan, M. A., D. M. Weary, and M. A. G. von Keyserlingk. 2011. Invited review: Effects of milk ration on solid feed intake, weaning, and performance in dairy heifers. J. Dairy Sci. 94:1071-1081. https://doi.org/10.3168/jds.2010-3733.

Laarman, A. H., and M. Oba. 2011. Short communication: Effect of calf starter on rumen $\mathrm{pH}$ of Holstein dairy calves at weaning. J. Dairy Sci. 94:5661-5664. https://doi.org/10.3168/jds.2011-4273.

McGuirk, S. M. 2008. Disease Management of Dairy Calves and Heifers. Vet. Clin. North Am. Food Anim. Pract. 24:139-153. https:// doi.org/10.1016/j.cvfa.2007.10.003.

Meale, S. J., F. Chaucheyras-Durand, H. Berends, L. L. Guan, and M. A. Steele. 2017. From pre- to postweaning: Transformation of the young calf's gastrointestinal tract 1. J. Dairy Sci. 100:5984-5995. https://doi.org/10.3168/jds.2016-12474.

Medrano-Galarza, C., S. J. LeBlanc, T. J. DeVries, A. Jones-Bitton, J. Rushen, A. Marie de Passillé, and D. B. Haley. 2017. A survey of dairy calf management practices among farms using manual and automated milk feeding systems in Canada. J. Dairy Sci. 100:6872-6884. https://doi.org/10.3168/jds.2016-12273.

Miller-Cushon, E. K., R. Bergeron, K. E. Leslie, and T. J. DeVries. 2013. Effect of milk feeding level on development of feeding behav- ior in dairy calves. J. Dairy Sci. 96:551-564. https://doi.org/10 $.3168 /$ jds.2012-5937.

Morrill, J. L., and A. D. Dayton. 1974. Effect of whey on calf starter palatability. J. Dairy Sci. 57:430-433. https://doi.org/10.3168/jds .S0022-0302(74)84909-X.

Morris, T. R. 1999. Experimental Design and Analysis in Animal Sciences. CABI Publishing.

Nielsen, P. P., M. B. Jensen, and L. Lidfors. 2008. Milk allowance and weaning method affect the use of a computer controlled milk feeder and the development of cross-sucking in dairy calves. Appl. Anim. Behav. Sci. 109:223-237. https://doi.org/10.1016/j.applanim.2007 .01 .015 .

NRC. 2001. Nutrient Requirements of Dairy Cattle. 7th rev. ed. National Academies Press.

Overvest, M. A., R. Bergeron, D. B. Haley, and T. J. DeVries. 2016. Effect of feed type and method of presentation on feeding behavior, intake, and growth of dairy calves fed a high level of milk. J. Dairy Sci. 99:317-327. https://doi.org/10.3168/jds.2015-9997.

Parsons, S. D., M. A. Steele, K. E. Leslie, D. L. Renaud, and T. J. DeVries. 2020. Investigation of weaning strategy and solid feed location for dairy calves individually fed with an automated milk feeding system. J. Dairy Sci. 103:6533-6556. https://doi.org/10 $.3168 /$ jds.2019-18023.

Raeth-Knight, M., H. Chester-Jones, S. Hayes, J. Linn, R. Larson, D. Ziegler, B. Ziegler, and N. Broadwater. 2009. Impact of conventional or intensive milk replacer programs on Holstein heifer performance through six months of age and during first lactation. J. Dairy Sci. 92:799-809. https://doi.org/10.3168/jds.2008-1470.

Reedman, C. N. 2021. Refining our understanding of the effects of disbudding on the welfare of dairy calves. $\mathrm{PhD}$ thesis. Department of Population Medicine, University of Guelph. https://hdl.handle .net $/ 10214 / 26346$.

Rosadiuk, J. P., T. C. Bruinjé, F. Moslemipur, A. J. Fischer-Tlustos, D. L. Renaud, D. J. Ambrose, and M. A. Steele. 2021. Differing planes of pre- and postweaning phase nutrition in Holstein heifers: I. Effects on feed intake, growth efficiency, and metabolic and development indicators. J. Dairy Sci. 104:1136-1152. https://doi .org/10.3168/jds.2020-18809.

Rosenberger, K., J. H. C. Costa, H. W. Neave, M. A. G. von Keyserlingk, and D. M. Weary. 2017. The effect of milk allowance on behavior and weight gains in dairy calves. J. Dairy Sci. 100:504-512. https://doi.org/10.3168/jds.2016-11195.

Schäff, C. T., J. Gruse, J. Maciej, M. Mielenz, E. Wirthgen, A. Hoeflich, M. Schmicke, R. Pfuhl, P. Jawor, T. Stefaniak, and H. M. Hammon. 2016. Effects of feeding milk replacer ad libitum or in restricted amounts for the first five weeks of life on the growth, metabolic adaptation, and immune status of newborn calves. PLoS One 11:e0168974. https://doi.org/10.1371/journal.pone.0168974.

Schlau, N., L. L. Guan, and M. Oba. 2012. The relationship between rumen acidosis resistance and expression of genes involved in regulation of intracellular $\mathrm{pH}$ and butyrate metabolism of ruminal epithelial cells in steers. J. Dairy Sci. 95:5866-5875. https://doi.org/ $10.3168 /$ jds.2011-5167.

Scoley, G., A. Gordon, and S. Morrison. 2019. Performance and behavioural responses of group housed dairy calves to two different weaning methods. Animals (Basel) 9:895. https://doi.org/10 $.3390 /$ ani9110895.

Steele, M. A., J. H. Doelman, L. N. Leal, F. Soberon, M. Carson, and J. A. Metcalf. 2017. Abrupt weaning reduces postweaning growth and is associated with alterations in gastrointestinal markers of development in dairy calves fed an elevated plane of nutrition during the preweaning period. J. Dairy Sci. 100:5390-5399. https:// doi.org/10.3168/jds.2016-12310.

Sweeney, B. C., J. Rushen, D. M. Weary, and A. M. de Passillé. 2010. Duration of weaning, starter intake, and weight gain of dairy calves fed large amounts of milk. J. Dairy Sci. 93:148-152. https:/ /doi.org/10.3168/jds.2009-2427.

Terré, M., M. Devant, and A. Bach. 2007. Effect of level of milk replacer fed to Holstein calves on performance during the preweaning 
period and starter digestibility at weaning. Livest. Sci. 110:82-88. https://doi.org/10.1016/j.livsci.2006.10.001.

Terré, M., F. Fabregas, and A. Bach. 2016. Effect of Axcelera-C on calf performance, intake, digestive development, and immune function during the first three months of life. J. Anim. Sci. 94(suppl_5):710. https://doi.org/10.2527/jam2016-1463.

Urie, N. J., J. E. Lombard, C. B. Shivley, C. A. Kopral, A. E. Adams, T. J. Earleywine, J. D. Olson, and F. B. Garry. 2018. Preweaned heifer management on US dairy operations: Part I. Descriptive characteristics of preweaned heifer raising practices. J. Dairy Sci. 101:9168-9184. https://doi.org/10.3168/jds.2017-14010.

Weary, D. M., J. Jasper, and M. J. Hötzel. 2008. Understanding weaning distress. Appl. Anim. Behav. Sci. 110:24-41. https://doi.org/ 10.1016/j.applanim.2007.03.025

Wickramasinghe, H. K. J. P., A. J. Kramer, and J. A. D. R. N. Appuhamy. 2019. Drinking water intake of newborn dairy calves and its effects on feed intake, growth performance, health status, and nutrient digestibility. J. Dairy Sci. 102:377-387. https://doi.org/ $10.3168 /$ jds.2018-15579.

Wilm, J., J. H. C. Costa, H. W. Neave, D. M. Weary, and M. A. G. von Keyserlingk. 2018. Technical note: Serum total protein and immunoglobulin $\mathrm{G}$ concentrations in neonatal dairy calves over the first 10 days of age. J. Dairy Sci. 101:6430-6436. https://doi.org/ $10.3168 /$ jds.2017-13553.
Winder, C. B., C. A. Bauman, T. F. Duffield, H. W. Barkema, G. P. Keefe, J. Dubuc, F. Uehlinger, and D. F. Kelton. 2018. Canadian National Dairy Study: Heifer calf management. J. Dairy Sci. 101:10565-10579. https://doi.org/10.3168/jds.2018-14680.

Winder, C. B., S. J. LeBlanc, D. B. Haley, K. D. Lissemore, M. A. Godkin, and T. F. Duffield. 2017. Clinical trial of local anesthetic protocols for acute pain associated with caustic paste disbudding in dairy calves. J. Dairy Sci. 100:6429-6441. https://doi.org/10 .3168/jds.2017-12724.

\section{ORCIDS}

S. D. Parsons $($ ㄴ https://orcid.org/0000-0002-7325-5093

M. A. Steele $\odot$ https://orcid.org/0000-0001-6941-6205

K. E. Leslie @ https://orcid.org/0000-0001-9804-2628

D. L. Renaud ๑ https://orcid.org/0000-0002-3439-3987

C. N. Reedman (1) https://orcid.org/0000-0003-3904-0993

C. B. Winder $\odot$ https://orcid.org/0000-0002-7314-3657

T. J. DeVries () https://orcid.org/0000-0001-9364-2456 